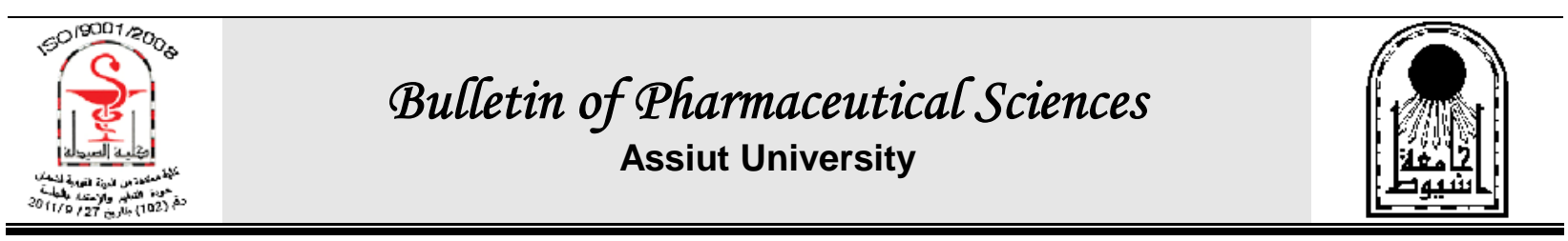

\title{
MACRO- AND MICROMORPHOLOGY OF THE AERIAL PARTS OF LANTANA MONTEVIDENSIS (SPRENG.) BRIQ. CULTIVATED IN EGYPT
}

\author{
M. A. Makboul, A. A. Attia, S. F. Farag and N. M. Kamal \\ Department of Pharmacognosy, Faculty of Pharmacy, Assiut University, Assiut, Egypt
}

\begin{abstract}
Lantana montevidensis (Spreng.) Briq. is a member of family Verbenaceae, that includes about 98 genera and more than 2600 species which are predominantly tropical or subtropical plants. The leaf infusions of the plant are used in folk medicine to treat fever, influenza, asthma, bronchitis, and many other diseases. Biological studies showed that the plant has antimicrobial and antiproliferative activities. No detailed information could be traced concerning the macroand micromorphology of the plant. This motivated the authors to carry out this study to identify the drug in both entire and powdered form.
\end{abstract}

\section{INTRODUCTION}

The family Verbenaceae (Verbain, Verbena or Vervian family), includes about 98 genera and more than 2600 species $^{1-3}$ distributed in tropical or subtropical regions. Members of family Verbenaceae are annual herbs, shrubs, or trees and climbers sometimes of a thorny xerophytic nature ${ }^{4}$.

The general features of the genus include that the stems may be scabrid-hairy or prickly. Leaves are simple, opposite decussate, usually dentate and serrate, exstipulate, petiolate or subsessile and mostly aromatic, toothed and glandular-punctuate. Inflorescence is axillary pedunclate, of contracted heads or dense cylindrical spikes. Fruits are small, purple, fleshy drupe, separating into two 1-locular pyrenes. Seeds are exalbuminous ${ }^{5}$. Triterpenoids, steroids, flavonoids, iridoid glycosides, oligosaccharides, phenylpropanoid glycosides and naphthoquinones have been reported as chemical constituents of different Lantana species $^{6-8}$.

Lantana montevidensis (Spreng.) Briq. is known as Weeping or Trailing Lantana. It was introduced as a ground covering ornamental plant as it is quick growing, drought-resistant and flowers freely for almost the whole year ${ }^{5}$. In folk medicine, it was employed in the treatment of broncho-pulmonary disease, headaches, sunstroke and fevers ${ }^{5}$. Also, leaf infusions of the plant are used in treatment of fever, influenza, asthma, bronchitis, and many other diseases. The methanolic extract of the leaf of the plant showed an antiproliferative activity against tumor cells and the flavonoid rich fraction was effective against human gastric adenocarcinoma, human uterine carcinoma, and melanoma cell lines ${ }^{9}$. Also, it was reported that the leaves' essential oil exhibited promising antimicrobial activity ${ }^{10 \& 11}$.

\section{Habitat}

Lantana montevidensis (Spreng.) Briq. (Fig. 1) is native to Brazil or Uruguay, largely found in tropical and sub-tropical environments and occasionally in temperate and semi-arid regions. It is a creeping, trailing, decumbent or scrambling woody herb or low shrub, often mat-forming with very short but profusely flowered branches ${ }^{5}$. 


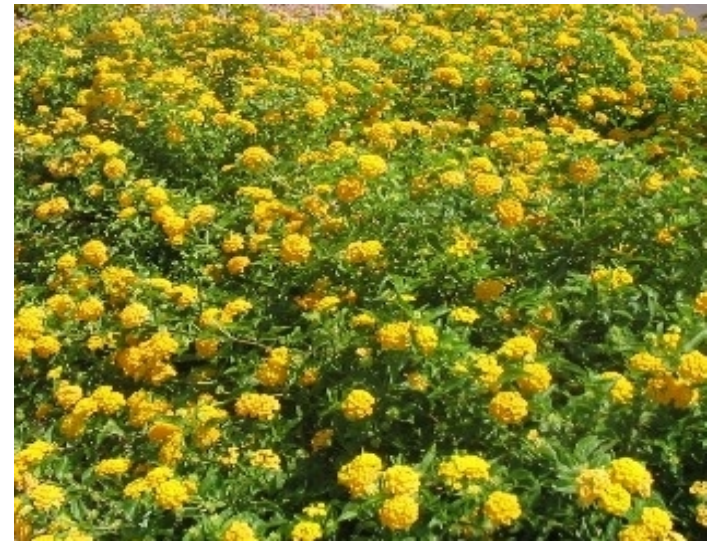

Fig. 1: Photo of the plant.

\section{Material}

Fresh samples of $L$. montevidensis (Spreng.) Briq. including leaves, stem, inflorescence and root were collected during the flowering stage in the period of February to November 2009, from the fields of the temporary building of Assiut University and kindly identified and authenticated by Prof. Dr. Abd-El Aziz Fayed, Professor of Taxonomy, Botany Department, Faculty of Science, Assiut University and Prof. Dr. Naeem E. Keltawy, Professor of Ornamental Horiculture and Floriculture, Faculty of Agriculture, Assiut University. Different organ samples were preserved in a mixture of alcohol (70\%)glycerin-water $(1: 1: 1 \mathrm{v} / \mathrm{v} / \mathrm{v})$ and stored in a tightly closed container. Other samples were separately air-dried and reduced to fine powder.

\section{THE LEAF}

\section{A- Macromorphology (Fig. 2A\&B)}

The leaves are opposite decussate, simple, exstipulate, petiolate with upper dark green surface and a lower paler one. Both surfaces are rough and pubescent. The lamina is ovate to lanceolate in shape with acute to acuminate apices. The margin is serrate to somewhat dentate. Venation is reticulate; veins are more prominent on the lower surface than the upper one and forming a chequered appearance. The leaf is coriaceous in texture and varies in size, about $3-4.5-6 \mathrm{~cm}$ in length and $1.2-2.2-3 \mathrm{~cm}$ in width in the middle portion. The petiole is cylindrical, pale green in colour and measures about $1-1.5-2 \mathrm{~cm}$ in length and $1.5-1.75-2 \mathrm{~mm}$ in diameter. Hairs are abundant on both surfaces of the petiole. The leaf has a characteristic agreeable aromatic odour and a slight bitter taste.

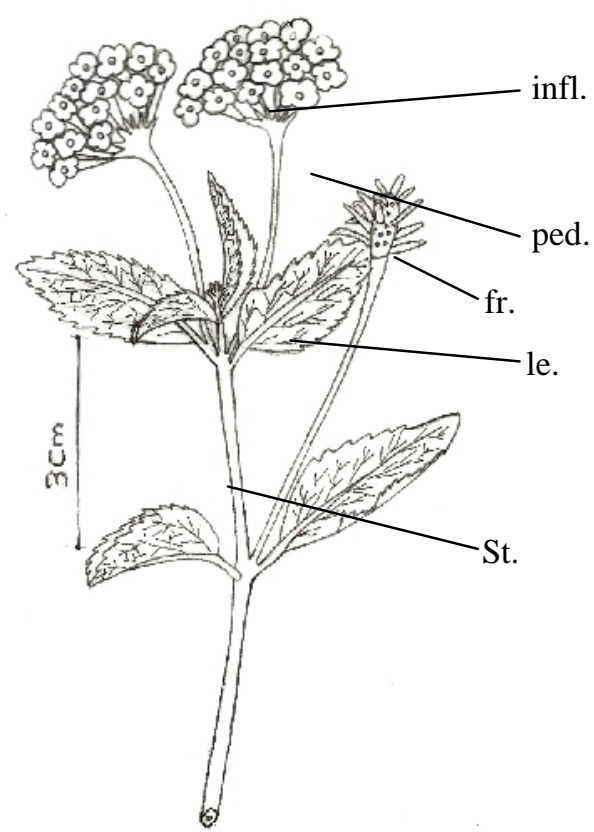

(A)

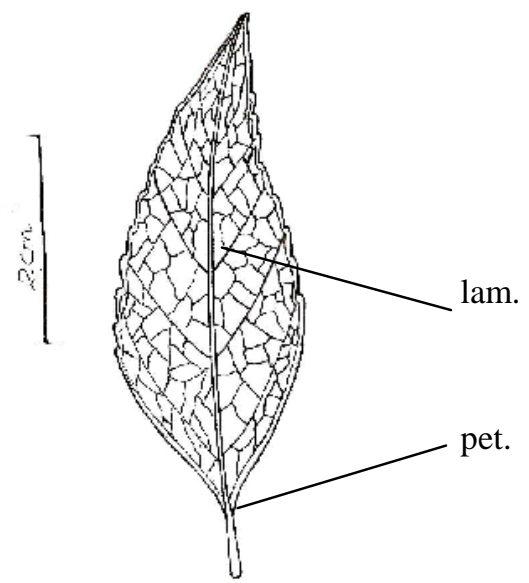

Fig. 2: (A) Macromorphology of the flowering branch. (B) Macromorphology of the leaf.

fr., fruit; infl., inflorescence; lam., lamina; le., leaf; ped., peduncle; pet., petiole; st., stem.

\section{B-Micromorphology}

The transverse section in the leaf (Fig. 3A) appears more or less biconvex in outline with the midrib bulging on the lower surface and showing a small ridge in the upper one. It shows a dorsiventral structure with an upper palisade consisting of two rows of columnar cells of variable size. The palisade is not continuous in midrib region where it is replaced by a subepidermal mass of collenchyma, another mass of collenchyma is present abutting on the lower epidermis. The 
midrib region shows a large main vascular bundle accompanied with one to five smaller ones. The pericycle is parenchymatous. Both the upper and lower epidermises are covered with glandular and non-glandular hairs which increase in number over the midrib region.

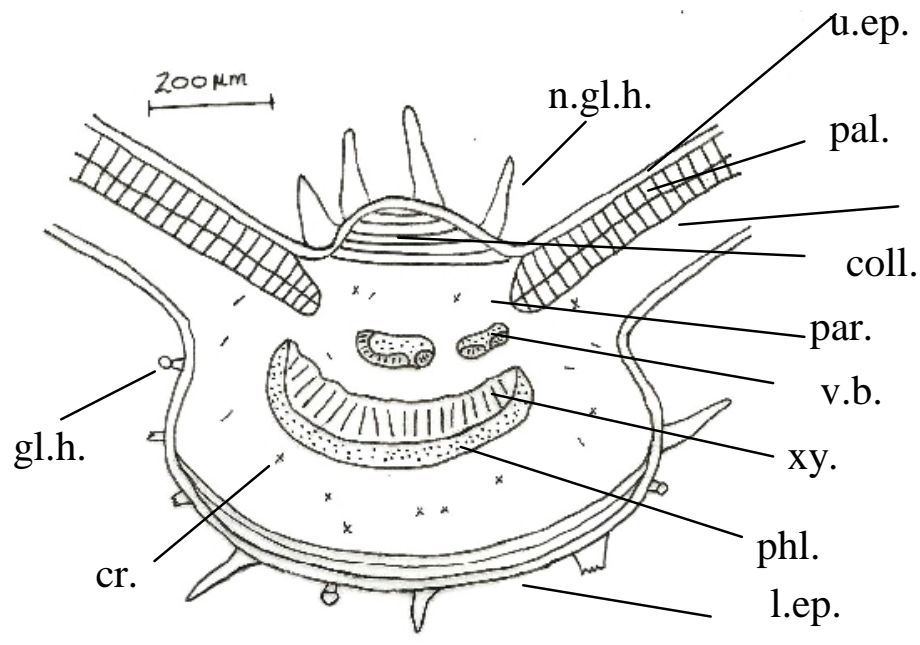

(A)

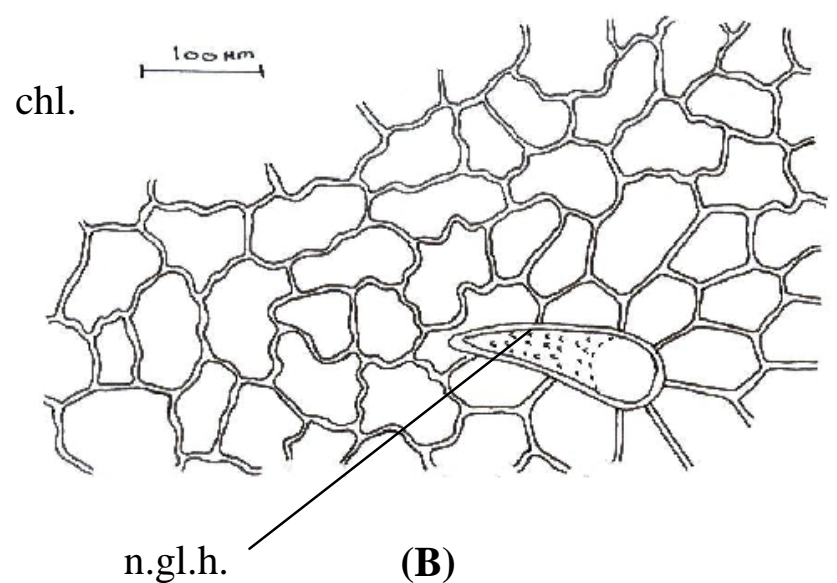

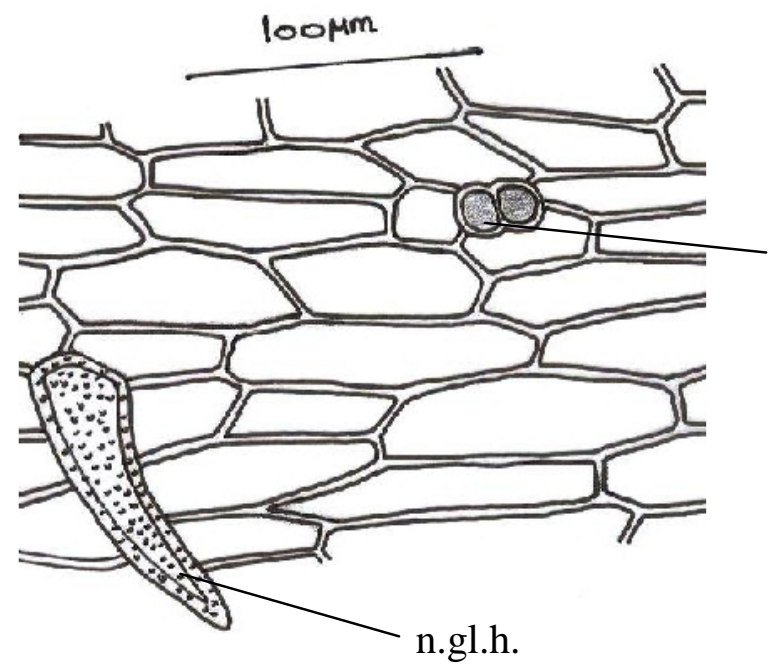

(C)

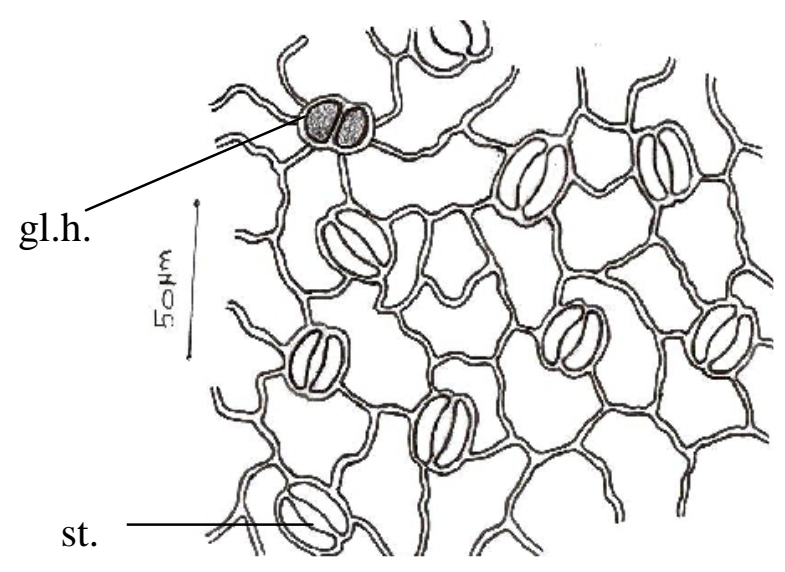

(D)

Fig. 3: (A) The diagrammatic T.S of the leaf.

(B) The upper epidermis of the leaf.

(C) The neural epidermis of the leaf.

(D) The lower epidermis of the leaf.

chl., chlorenchyma; coll., collenchyma; cor., cortex; cr., crystal; gl.h., glandular hairs; l.ep., lower epidermis; mes., mesophyll; n.gl.h., non-glandular hair; pal., palisade; par.,.parenchyma; ph., phloem; sto., stomata; u.ep., upper epidermis; v.b., vascular bundle; xy., xylem. 


\section{The upper epidermis}

The upper epidermis (Figs. 4\&5) is formed of one row of tangentially elongated cells and covered with thick smooth cuticle. In surface view (Fig. 3B), the cells appear polygonal, isodiametric to subrectangular slightly elongated with straight to curved or slightly wavy anticlinal walls. Those in the neural region (Fig. 3C) are longer, axially elongated with more straight anticlinal wall. The stomata are absent in the upper epidermis. Abundant trichomes are present of both covering and glandular types. The covering trichomes are unicellular, rarely bicellular and covered with usually warty cuticle. The unicellular covering trichomes are conical in shape with wide lumens, sometimes solid and acute to acuminate bent apices or narrow lumens and acute apices. Sometimes, they show cystoliths of calcium carbonate in their enlarged bases. The glandular hairs are numerous, with globular unicellular, bicellular (divided vertically as those of digitalis) ${ }^{12 \& 13}$ and multicellular heads of 3 to 4 cells and the stalks may be unicellular or bicellular uniseriate.

\section{The lower epidermis}

The lower epidermis (Figs. 4\&5) is formed of one row of square cells and are covered with relatively thick smooth cuticle. In surface view (Fig. 3D), they are polygonal, mostly isodiametric with wavy or sinuated anticlinal walls, they are smaller than those of the upper epidermis. Numerous stomata of the anomocytic type are present and surrounded by 3 to 4 epidermal cells. The stomata are rounded to oval in shape. The trichomes are exactly similar to those of the upper epidermis in all aspects except that they are present in larger number.

\section{The mesophyll (Fig. 4)}

The mesophyll is heterogenous consisting of an upper zone of palisade layer interrupted by a mass of collenchymatous cells in the midrib region. The palisade layer consists of two rows of columnar, cylindrical thin walled cells with intercellular spaces and containing chloroplasts. The spongy tissue is formed of 34 rows of more or less rounded thin-walled chlorenchymatous cells with wide intercellular spaces. Many cells contain brown resinous matter which dissolves in ethanol $(70 \%)$ and re-precipitated on addition of water ${ }^{13}$. The mesophyll is traversed by separated strands of small vascular bundles representing the lateral veins.

\section{Cortical tissue (Fig. 5)}

The cells surrounding the vascular bundle are rounded to subrectangular parenchyma with wide intercellular spaces. Many of these cells show irregular masses of resinous brown matter that dissolves in ethanol and reprecipitate in water as well as prisms and clusters of calcium oxalate. There are 2 masses of subepidermal collenchyma, one above the bundle and formed of 3-4 rows of rounded or somewhat angular shining small cells and the other is below the bundle, abutting on the lower epidermis and consists of 2-3 rows.

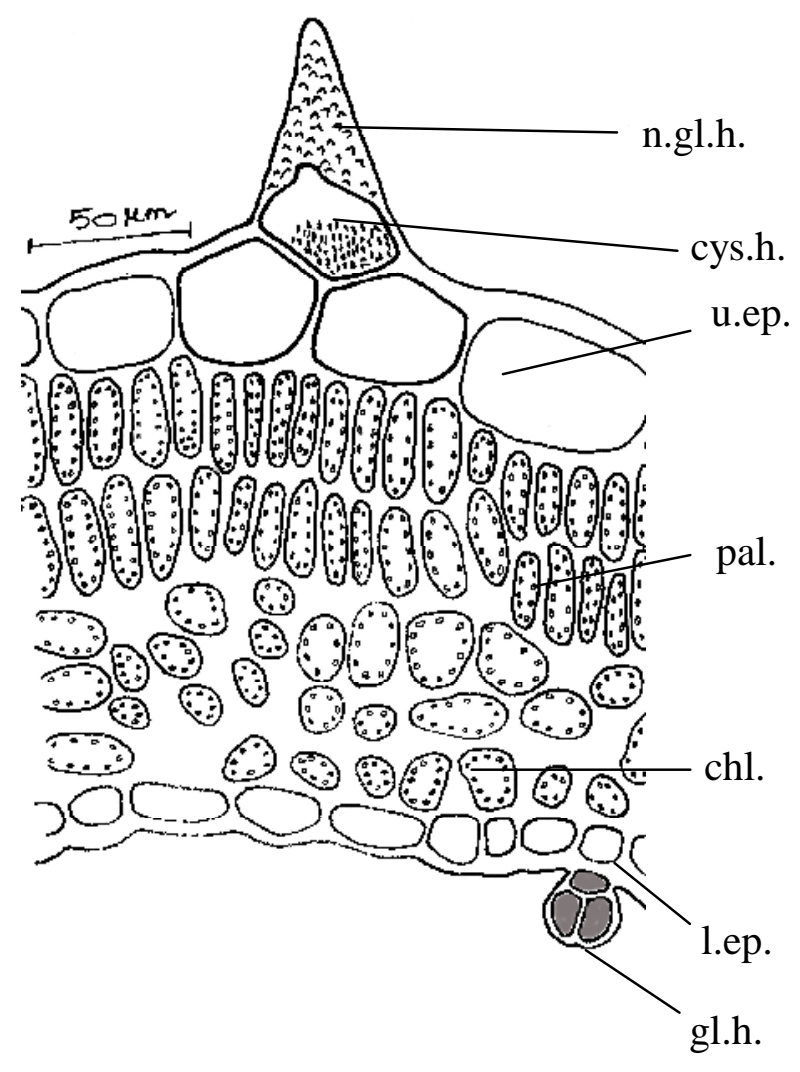

Fig. 4: The T.S. in the lamina of the leaf.

chl., chlorenchyma; cys.h., cystolithic hair; gl.h., glandular hairs; l.ep., lower epidermis; n.gl.h., non-glandular hair; pal., palisade; u.ep., upper epidermis. 


\section{Vascular system (Fig. 5)}

It is represented by a large central crescent shaped vascular bundle and from 2 to 5 smaller ones situated in its upper side. The bundles are collateral formed of an upper xylem and a lower phloem, but some of the small bundles are concentric with an outer xylem surrounding a phloem zone and few central parenchymatous cells are sometimes present representing pith. The xylem consists mainly of spiral, annular and scalariform lignified vessels. The phloem is narrow and consists of thin walled shining soft cellulosic elements. The cambium is indistinguishable. The pericycle is formed of 2 to 3 rows of thin walled parenchymatous cells.
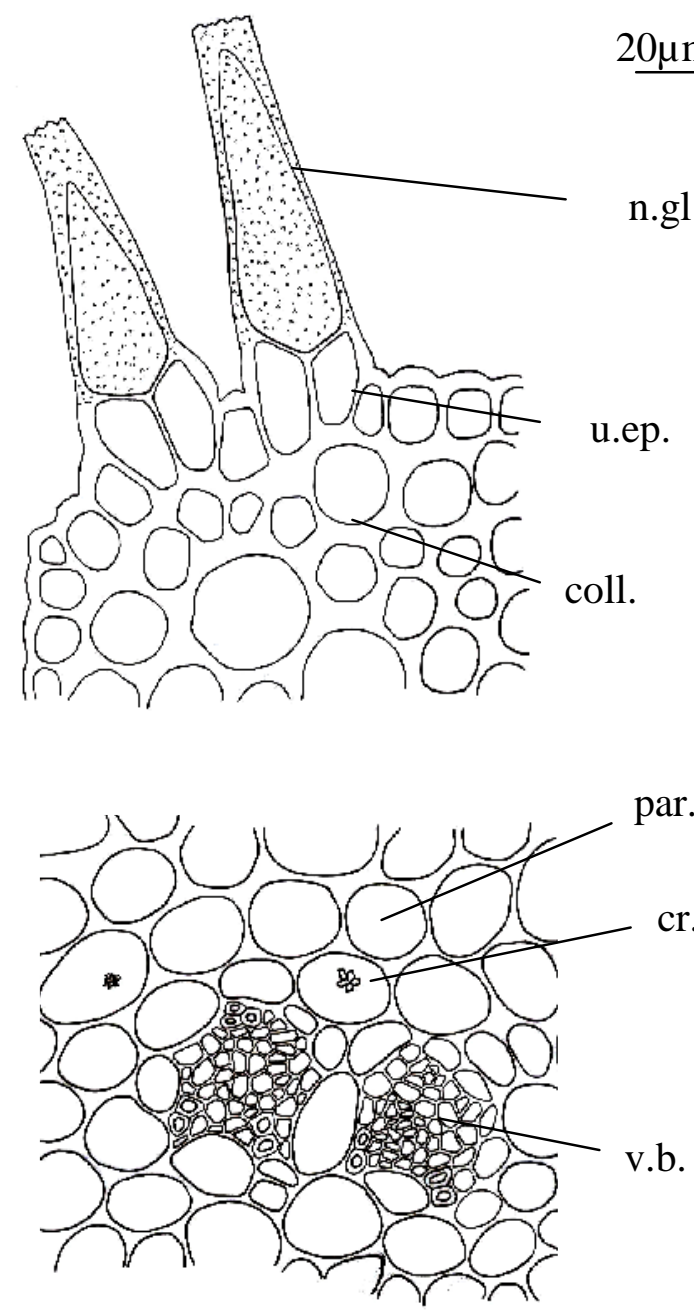

gl.h.

ep.
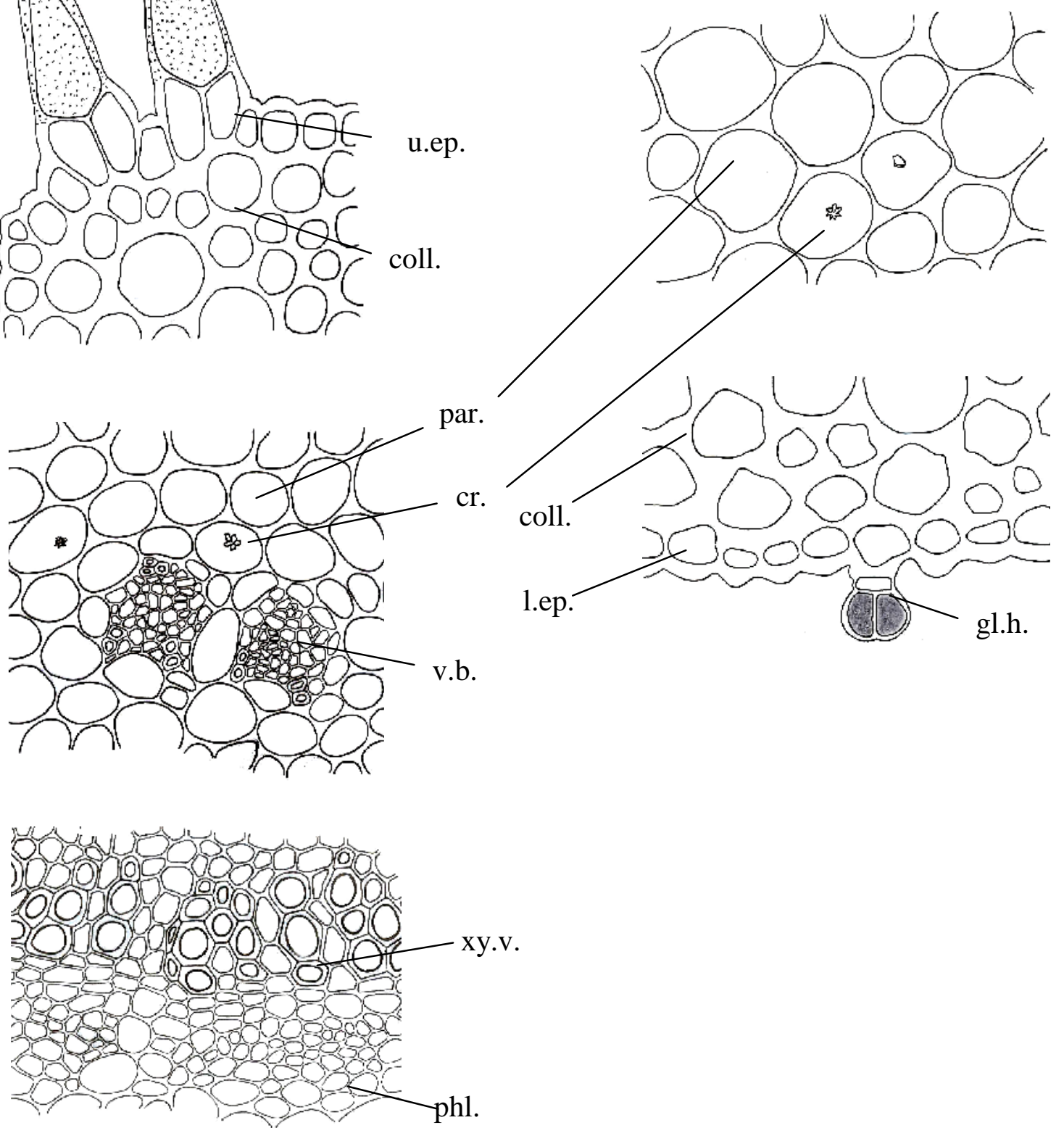

Fig. 5: The detailed T.S. in the midrib of the leaf.

coll., collenchyma; cr., crystal; gl.h., glandular hair; l.ep., lower epidermis; n.gl.h., non-glandular hair; par., parenchyma; phl., phloem; u.ep., upper epidermis; v.b., vascular bundle; xy.v., xylem vessel. 


\section{The petiole}

\section{Micromorphology}

The transverse section of the petiole (Fig. $6 \mathrm{~A})$ is more or less planoconvex to concavoconvex. It has an outer layer of epidermal cells which are covered with thick smooth cuticle, carrying glandular and nonglandular hairs. The epidermal cells are followed by cortical tissue which is composed of 3 to 4 rows of angular collenchymatous cells, followed by a wide parenchymatous zone containing prismatic and cluster crystals of calcium oxalate. The vascular system is formed of a main crescent shaped vascular bundle; in addition to 3 to 5 smaller vascular bundles similar in structure to that of the leaf.

\section{The upper epidermis}

The upper epidermis (Fig. 7) consists of one row of rectangular to subrectangular cells and covered with thick smooth cuticle. In surface view (Fig. 6B), they are polygonal mostly axially elongated with straight, relatively thick anticlinal walls. Trichomes of both covering and glandular types are of common occurrence, which are similar to those of the lamina. Stomata are rare and if present, they are of the rananculaceous type and similar to those of lamina in shape and size. The cells contain prismatic and cluster crystals of calcium oxalate.

\section{The lower epidermis}

The lower epidermis (Fig. 7) is formed of one row of cells, which appear square or subrectangular and covered with thick smooth cuticle. In the surface view (Fig. 6C), the cells are polygonal rectangular to subrectangular usually axially elongated with straight relatively thin anticlinal walls. Stomata are rare. Numerous trichomes of both types are present and they are identical to those of the upper epidermis. Clusters and minute prismatic crystals of calcium oxalate, similar to those of the upper epidermis, are present in many cells.

\section{Cortical tissue (Fig. 7)}

The cortical tissue is formed of 3-5 rows of angular collenchymtous cells. They are followed by 4-6 rows of rounded to polygonal parenchymatous cells with wide intercellular spaces. The cells contain resin, starch and calcium oxalate crystals. These contents are similar to those of the lamina.

\section{Vascular system (Fig. 7)}

It is similar to that of the lamina and no great difference between the two vascular systems. The vascular bundle is formed of a large collateral crescent shaped vascular strand. The xylem consists of radial rows of lignified spiral, annular and scalariform vessels and wood parenchyma. The phloem is formed of a narrow zone of soft, small and thin walled elements below the xylem. The cambium is hardly distinguishable. The pericycle is formed of 2 rows of thin walled parenchyma cells. In addition, 3-5 smaller vascular bundles are situated at the upper side of the large crescent shaped vascular bundle.

\section{The powdered leaf (Fig. 8)}

Dark green in colour, with characteristic agreeable aromatic odour and somewhat bitter astringent taste and it is characterized by the following:

1- Fragments of the upper epidermis of the lamina which appear polygonal, isodiametric to subrectangular slightly elongated with straight to curved or slightly wavy anticlinal walls. The cells are covered with thick smooth cuticle. The stomata are absent but abundant trichomes are present of both covering and glandular types. The covering trichomes are unicellular, rarely bicellular and covered with warty cuticle. The unicellular trichomes are conical in shape with wide lumens, sometimes solid and acute to acuminate bent apices or narrow lumens and acute apices. Occasionally, they show cystoliths of calcium carbonate in their enlarged bases. The glandular hairs are numerous, with globular unicellular, bicellular (divided vertically as those of digitalis) and multicellular heads of 3 to 4 cells and the stalks may be unicellular or bicellular uniseriate.

2- Fragments of the lower epidermis of the lamina which appear polygonal, mostly isodiametric with wavy or sinuated anticlinal walls. The cells are covered with relatively thick smooth cuticle. Numerous rounded to ovate stomata of the anomocytic type are present. The trichomes are exactly similar to those of the upper epidermis in all respects. 


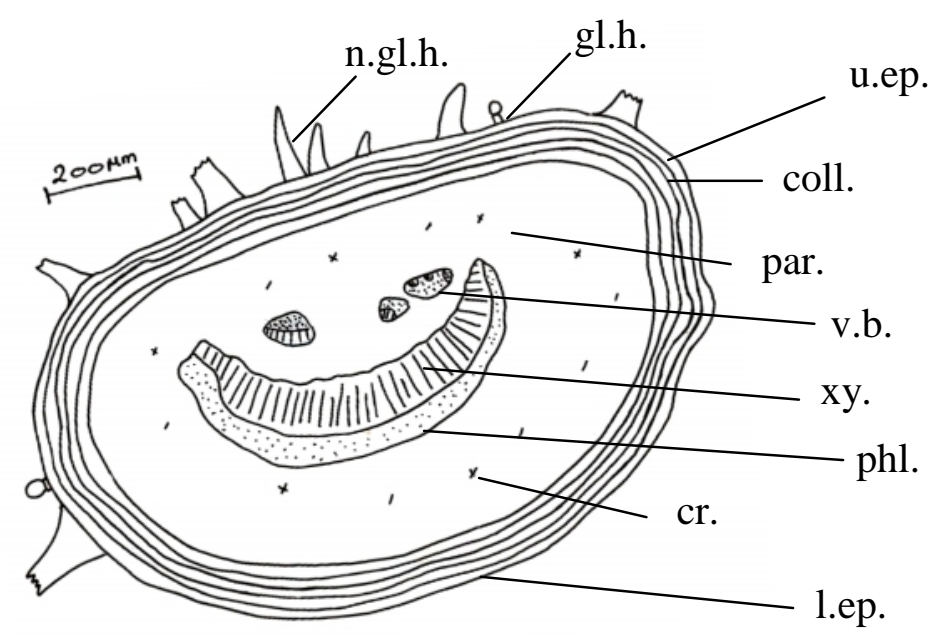

(A)

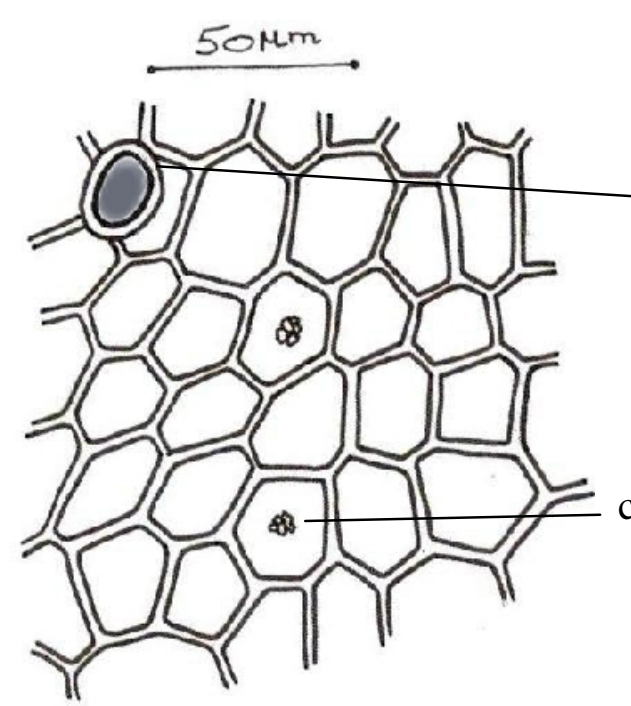

(B) gl.h.

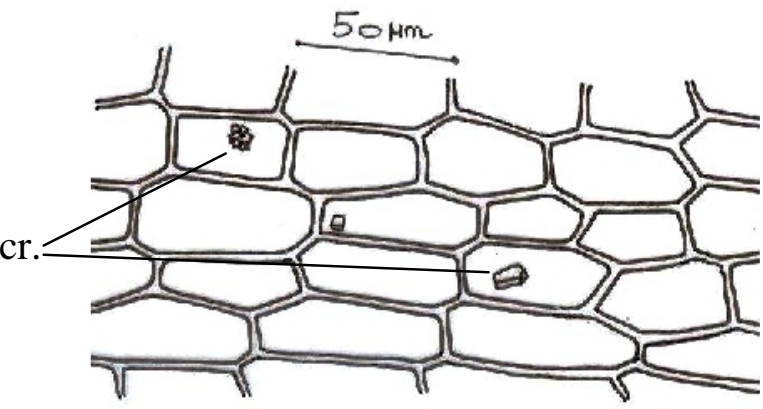

(C)

Fig. 6: (A) Diagrammatic T.S. of the petiole.

(B) Upper epidermis of the petiole.

(C) Lower epidermis of the petiole.

coll., collenchyma; cr., crystal; gl.h., glandular hair; l.ep., lower epidermis; n.gl.h., non-glandular hair; par., parenchyma; phl., phloem; u.ep., upper epidermis; v.b., vascular bundle; xy., xylem. 

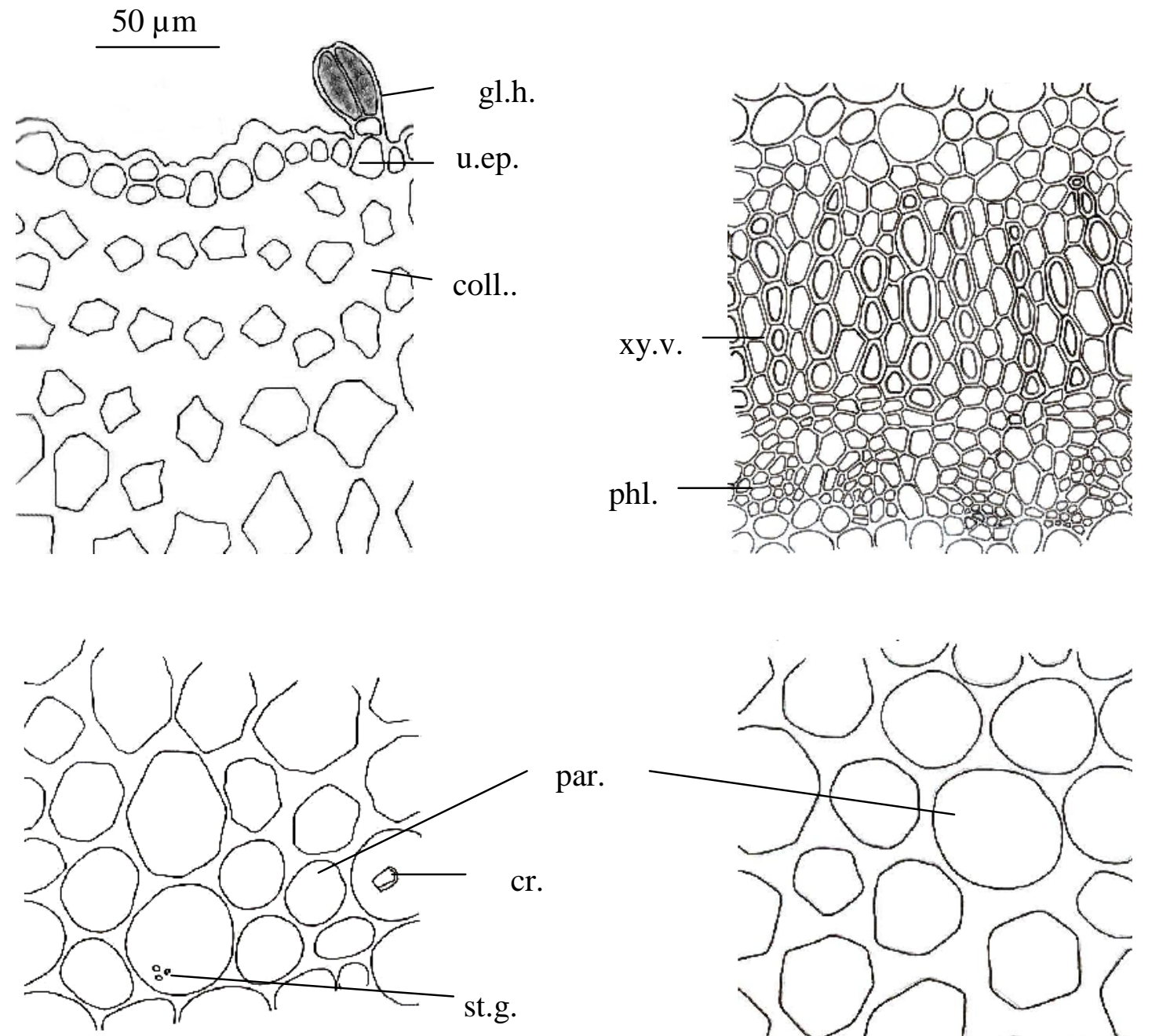

par.
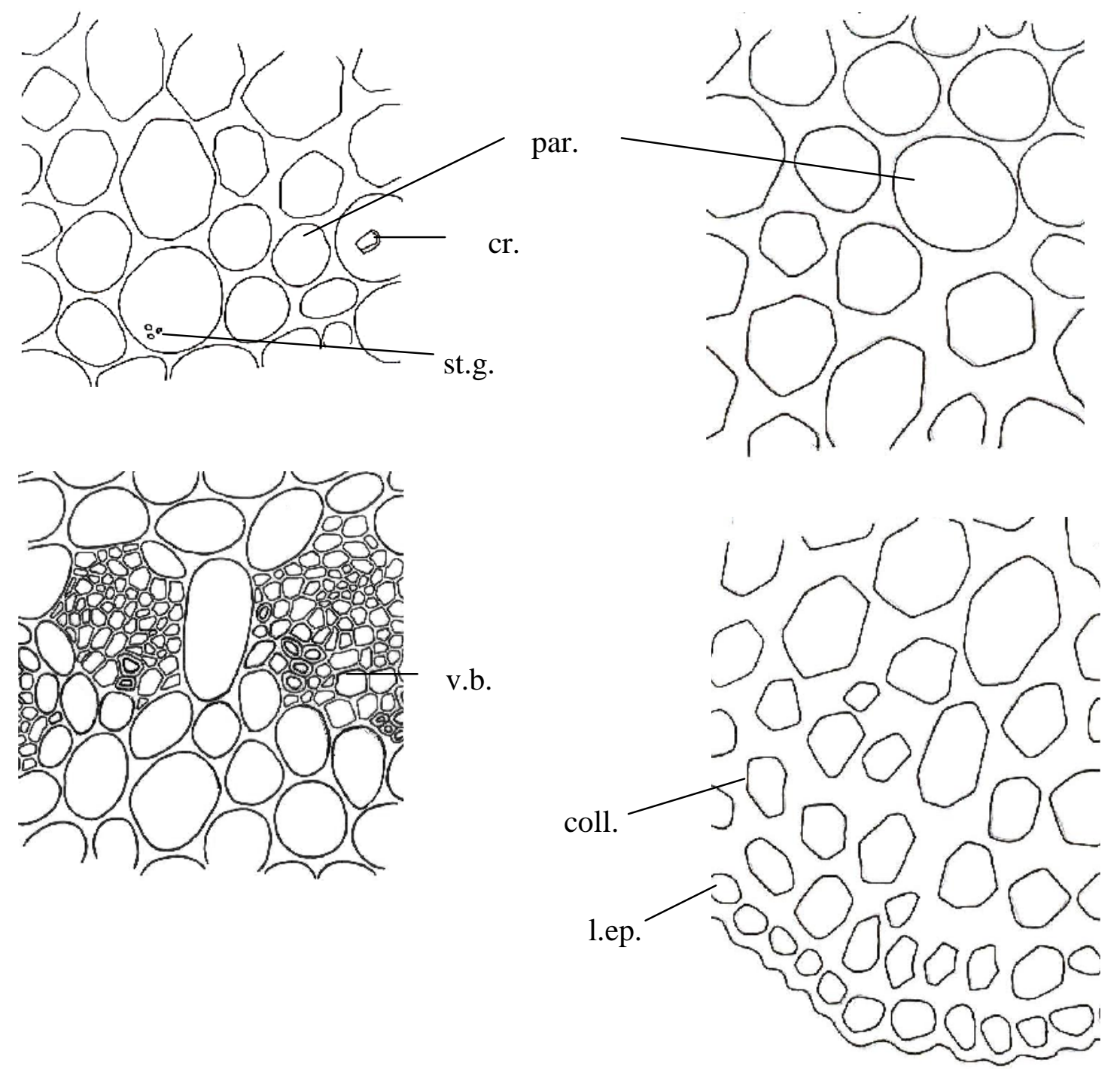

Fig. 7: The detailed T.S. of the petiole.

coll., collenchyma; cr., crystal; gl.h., glandular hair; l.ep., lower epidermis; par., parenychyma; phl., phloem; st.g., starch granules; u.ep., upper epidermis; v.b., vascular bundle; xy.v., xylem vessel. 


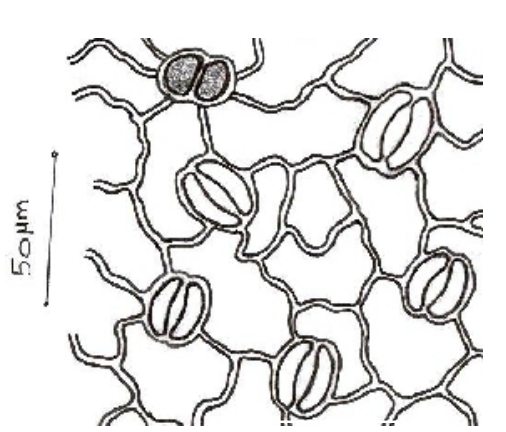

1.ep.

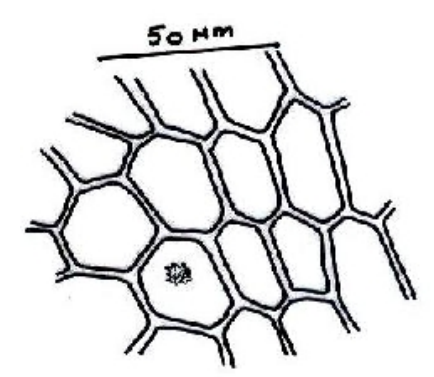

1.ep.pet.

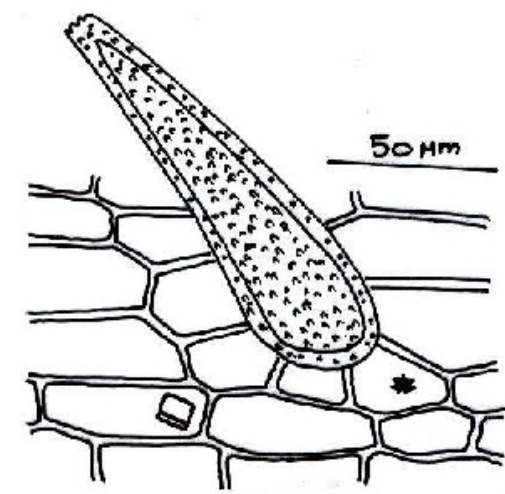

u.ep.pet.

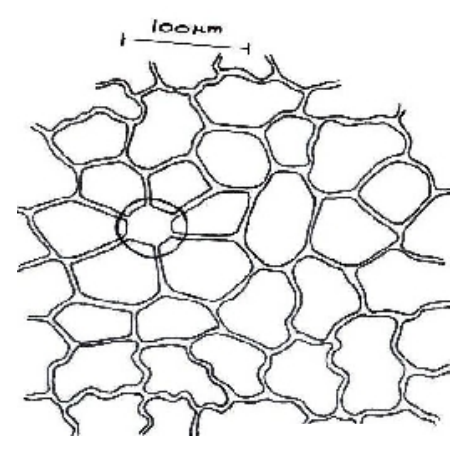

u.ep.

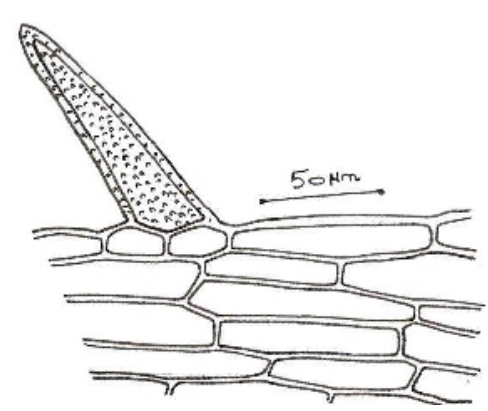

ne.ep.
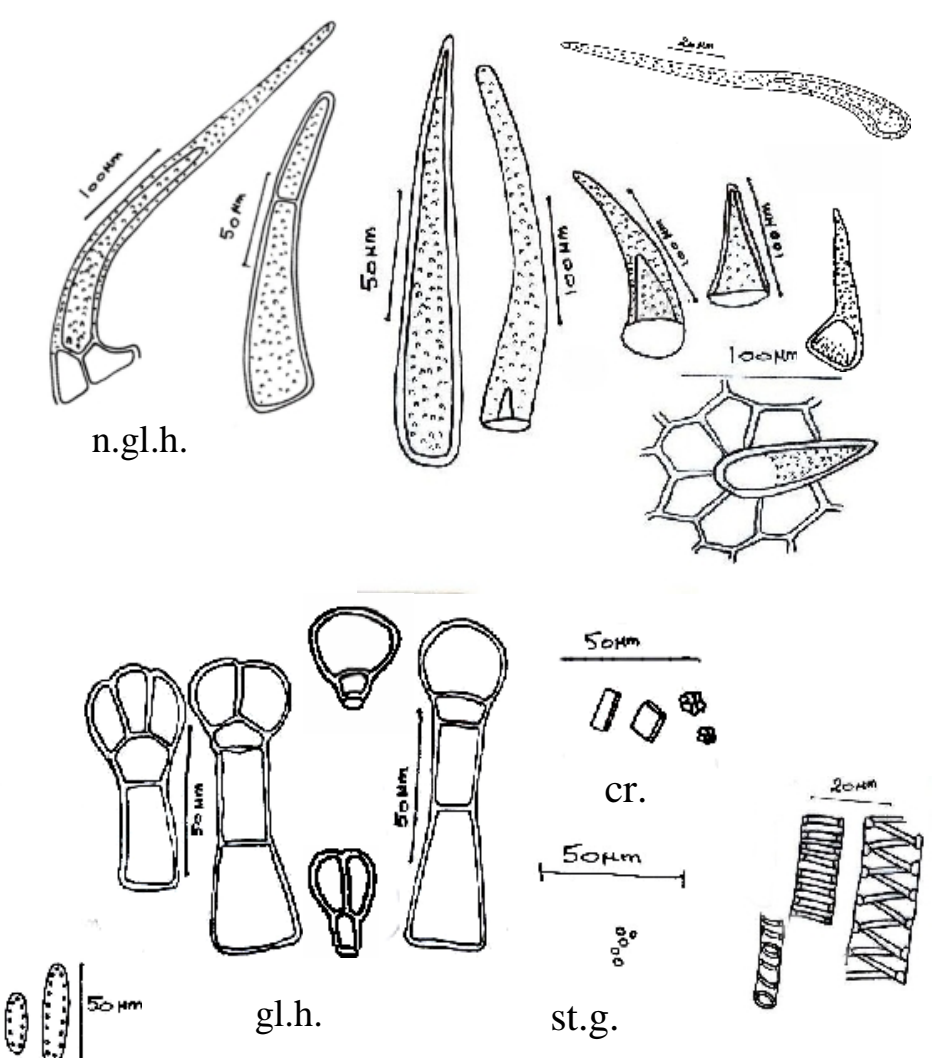

xy.v.

Fig. 8: The powder of the leaf.

cic., cicatrix; .cr., crystals; gl.h., glandular hair; l.ep., lower epidermis; ne.ep., neural epidermis; n.gl.h., non-glandular hair; pal., palisade; l.ep.pet., lower epidermis of petiole; u.ep.pet.., upper epidermis of petiole; st.g., starch granules; u.ep., upper epidermis; xy.v., xylem vessel. 
3- Fragments of the upper epidermis of the petiole, they appear polygonal mostly axially elongated with straight, thick anticlinal walls. They are covered with thick smooth cuticle. Trichomes of both covering and glandular types are of common occurrence, which are similar to those of the lamina in all respects. Stomata are rare and if present, they are of the rananculaceous type and similar to those of lamina. The cells contain minute prismatic and cluster crystals of calcium oxalate.

4- Fragments of the lower epidermis of the petiole which appear polygonal, rectangular to subrectangular usually axially elongated with straight thin anticlinal walls. The cells are covered with thick smooth cuticle. Stomata are rare. Hairs of both types are present and they are exactly identical to those of the upper epidermis in all respects. Clusters and prismatic crystals of calcium oxalate, exactly similar to the upper epidermis, are present in many cells.

5- Fragments of epidermal cells of both surfaces of the midrib region which are polygonal in surface view, axially elongated with straight anticlinal walls, carrying both glandular and non-glandular trichomes similar to those of the upper epidermis in all respects.

6- Fragments of mesophyll tissue with green columnar palisade cells and spongy parenchyma.

7- Scattered entire or fractions of glandular and non-glandular hairs.

8- Fragments showing lignified xylem vessels with spiral, annular and scalariform thickening.

9- Scattered clusters and prisms of calcium oxalate either free or enclosed in parenchymatous cells.

10- Few starch granules, either free or in parenchyma cells may be found.

\section{THE STEM}

\section{A- Macromorphology (Fig. 2A)}

The stem is creeping, perennial, quadrangular in outline at upper part and cylindrical at the lower one, solid and reaching 1-2 $\mathrm{m}$ in length and $4-5 \mathrm{~mm}$ in diameter but rarely reach more than $0.5 \mathrm{~m}$ in height. It carries internodes, measuring from 3 to $6 \mathrm{~cm}$ in length. The stems show no prickles. The younger parts of the stems are green in colour with hairy surface, have slight aromatic odour and slightly bitter taste, while the older parts are rough in surface, light brown in colour, odourless and slightly bitter taste. The stem is monopodially branched and rooting at the nodes that touch the soil.

\section{B- Micromorphology}

\section{1-Young stem}

A transverse section in the young stem (Fig. 9A) is more or less quadrangular in outline showing an epidermis, followed by a comparatively narrow parenchymatous cortex with a collenchymatous mass in the ridges. The inner most layer of the cortex, the endodermis, is somewhat distinguishable and showing starch granules. The pericycle is formed of a more or less complete ring of groups of lignified fibers, which are interrupted by thin walled parenchymatous cells especially in the furrows. The pericyclic zone surrounds the central cylinder, which is formed of a complete ring of vascular elements, enclosing wide pith. The phloem region is narrow while the xylem region is comparatively wide, and with a primary xylem projecting in the medulla and being separated from the phloem by a zone of cambiform cells. The phloem and the xylem are radially traversed by numerous medullary rays. Small starch granules as well as crystals of calcium oxalate are present in the parenchyma of the cortex and pith.

\section{The epidermis}

The epidermis (Fig. 10) consists of one row of square to subrectangular cells and covered with thick smooth cuticle. In surface view (Fig. 9B), they are axially elongated subrectangular with more or less straight or slightly curved anticlinal walls. Stomata of the rananculaceous type are present, which are more abundant on the furrows. Numerous unicellular covering trichomes are present with broad bases and acute to acuminate apices. They are covered with warty cuticle. The glandular trichomes are of two types, one has a unicellular stalk and a bicellular head (divided vertically as that of the digitalis) ${ }^{12 \& 13}$ and the 
other has a bicellular stalk and multicellular head of 3-5 cells.

\section{The cortex (Fig. 10)}

It is composed of few rows of rounded parenchyma and showing subepidermal masses of collenchyma, formed of 2 to 5 rows of rounded to angular shining cells on the ridges. The cells contain clusters and prismatic crystals of calcium oxalate as well as minute starch granules which are mainly simple. The inner most layer of the cortex, the endodermis, is formed of one row of tangentially elongated cells containing minute starch granules.

\section{The pericycle (Fig. 10)}

It consists of a more or less complete ring of lignified fibers which is interrupted in the furrows by parenchyma. The groups of fibers are well developed under the ridges. These fibers have relatively thin refractive walls, comparatively wide lumens and pointed to acuminate apices. Few of them are septated with one to two transverse septa dividing their lumens. Also, few of them contain cluster crystals of calcium oxalate in their lumens.

\section{The vascular system (Fig. 10)}

It shows a wide continuous ring traversed by narrow rays and formed mainly of secondary elements.

The phloem: is formed of a narrow ring, consisting of shining thin walled soft, cellulosic elements of sieve tubes, companion cells and phloem parenchyma. The phloem parenchyma is thin walled somewhat rounded and containing occasional cluster crystals of calcium oxalate similar to those present in the cortex.

The cambium: cambial zone is indistinct and rapidly differentiated into 2ry phloem and 2ry xylem cells. It is formed of 1-2 rows of cellulosic thin walled cambiform cells, which are subrectangular, tangentially and radially arranged.

The secondary xylem: It consists of lignified, pitted and thick walled radially arranged elements. The vessels are mainly solitary or in small groups of 2 to 3, usually with long segments and show simple pits. They are accompanied by numerous lignified tracheids, fibrous tracheids and few tracheidal vessels bearing simple pits. The wood parenchyma occurs usually in vertical rows and the cells are subrectangular and axially elongated. The medullary rays are usually uniserriate, sometimes biserriate. In the xylem region, the cells of medullary rays are radially elongated, subrectangular with thick, pitted lignified walls but in the phloem region they are non-lignified thin walled parenchyma. The wood fibers have wide lumens, thick walls and blunt to rounded ends.

The primary xylem: It is formed of few lignified xylem vessels and cellulosic thin walled parenchyma.

\section{The pith (Fig. 10)}

It is wide, parenchymatous, consisting usually of large, polygonal to rounded, isodiametric cells with moderately thin walls. It contains prismatic and cluster crystals of calcium oxalate as well as minute simple starch granules similar to those of the cortex in all aspects.

\section{2-Old stem}

A transverse section (Fig. 11A\&B) in the old stem is more or less circular in outline. The cork arises lately in the pericycle and consists of several, usually irregular, rows of subrectangular cells with lignified brown and thick walls. In surface view, they appear polygonal and mainly isodiametric. The phloem consists of shining thin walled soft, cellulosic elements of sieve tubes, companion cells, phloem parenchyma and isolated groups of phloem fibers arise in the secondary phloem. The phloem fibers have relatively narrow lumens, thick shining walls showing funnel shaped pits $^{13}$ and acute tapering ends. The xylem is formed of lignified elements. It consists of large vessels, wood fibers, tracheids, tracheidal vessels and wood parenchyma. The medullary rays are mainly uniserriate sometimes biserriate. They are radially elongated, subrectangular with thick pitted lignified walls in the xylem region, but they are non-lignified thin walled parenchyma in the phloem region. The pith consists of parenchyma cells which are sometimes of pitted walls, containing crystals of calcium oxalate and simple starch granules. 


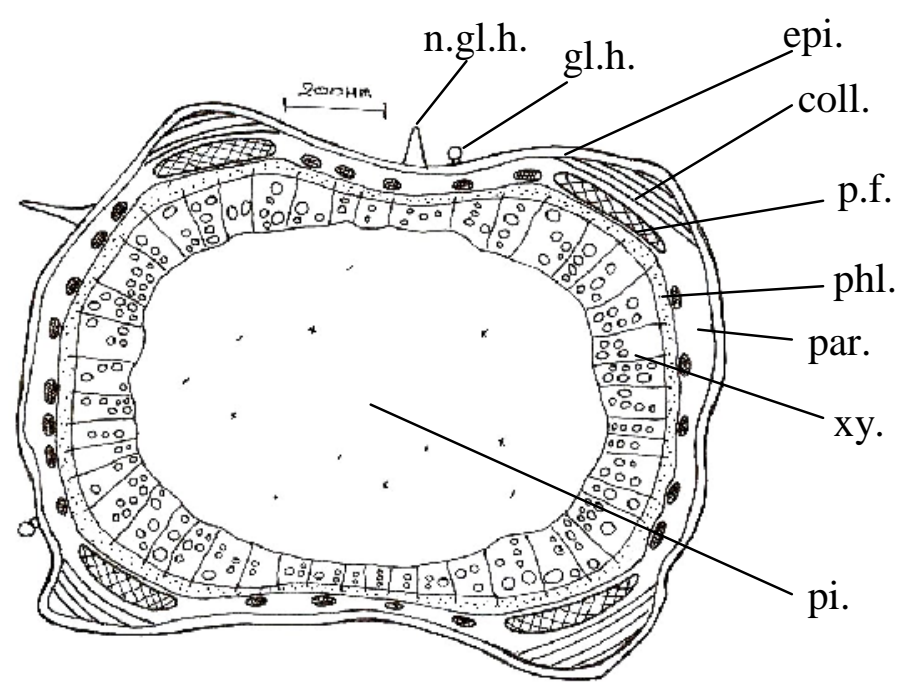

(A)

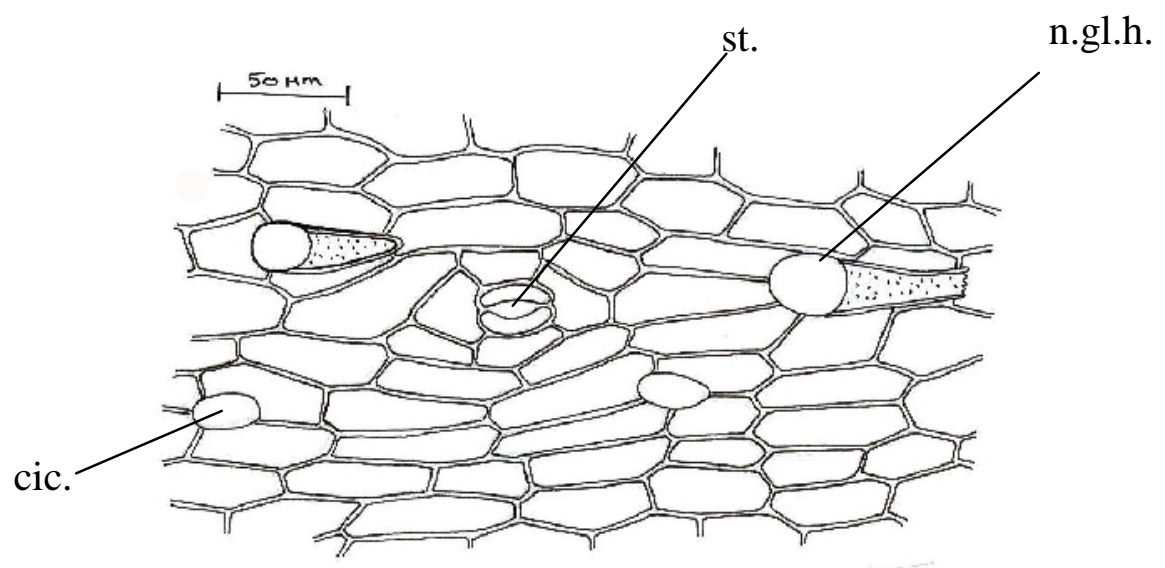

(B)

Fig. 9: (A) The diagrammatic T.S. of the young stem

(B) The epidermal cells of the young stem.

cic., cicatrix; coll., collenchyma; epi., epidermis; gl.h., glandular hair; n.gl.h., non-glandular hair; par., parenchyma; p.f., pericyclic fibre; phl., phloem; pi., pith; st., stomata; xy., xylem. 

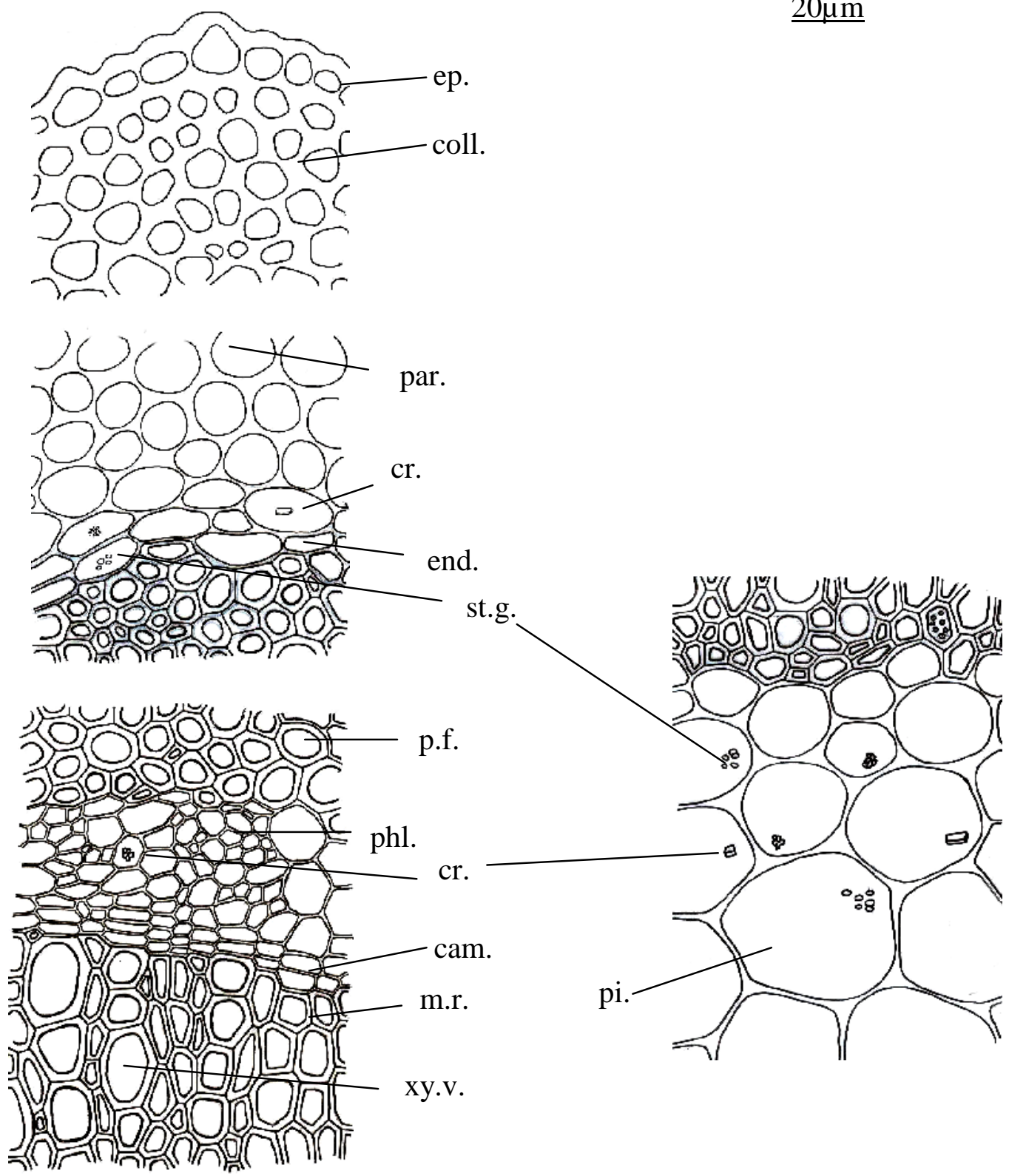

Fig. 10: The detailed T.S of the young stem.

cam., cambium; coll., collenchyma; end., endodermis; ep., epidermis; m.r., medullary ray; par., parenchyma; p.f., pericyclic fiber; phl., phloem; pi., pith; xy.v., xylem vessel. 


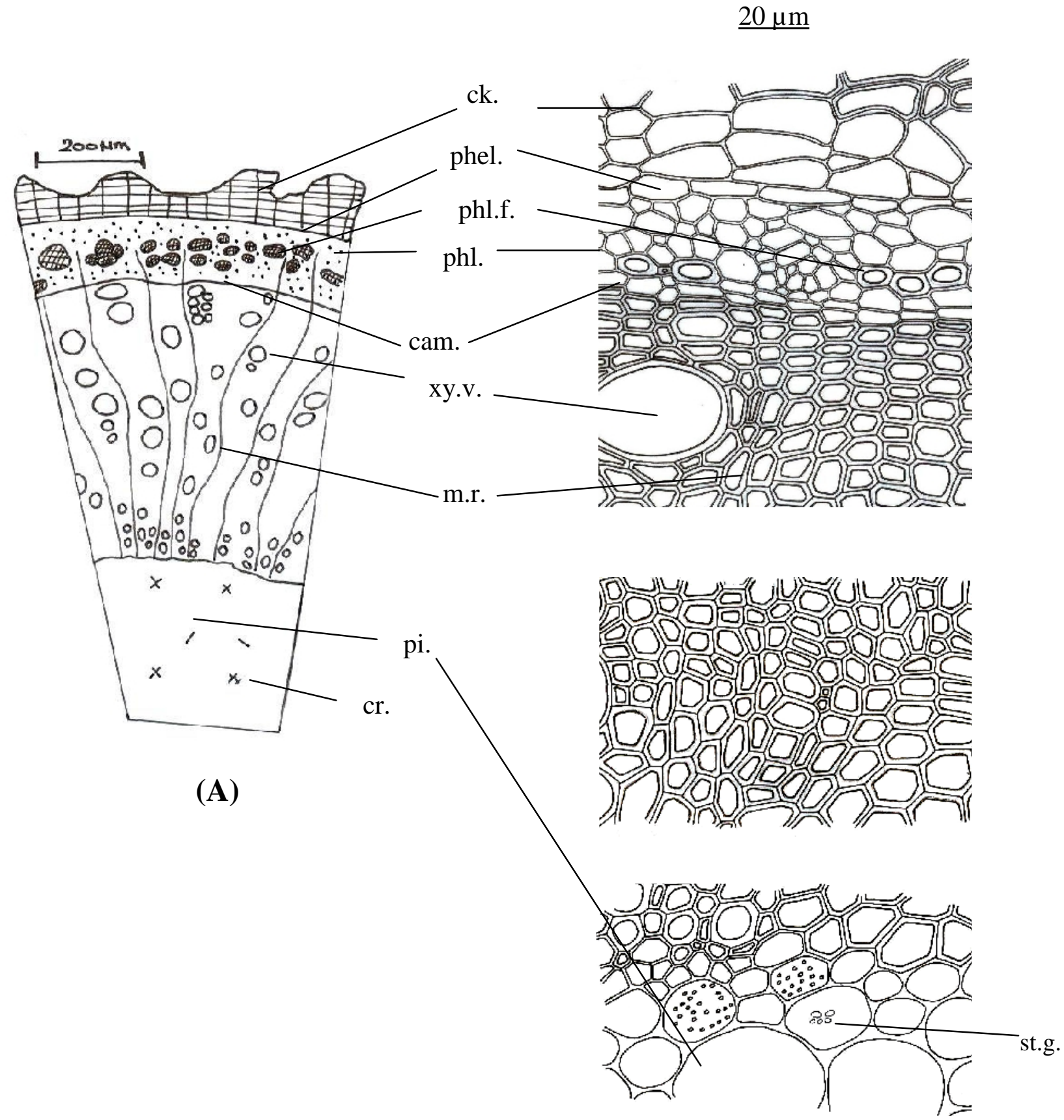

(B)

Fig. 11: (A) Diagrammatic T.S. of old stem.

(B) The detailed sector of the old stem.

cam., cambium; ck., cork; m.r., medullary rays; phel., phellogen; pi., pith; phl., phloem; phl.f., phloem fiber; st.g., starch granules; xy.v, xylem vessel. 

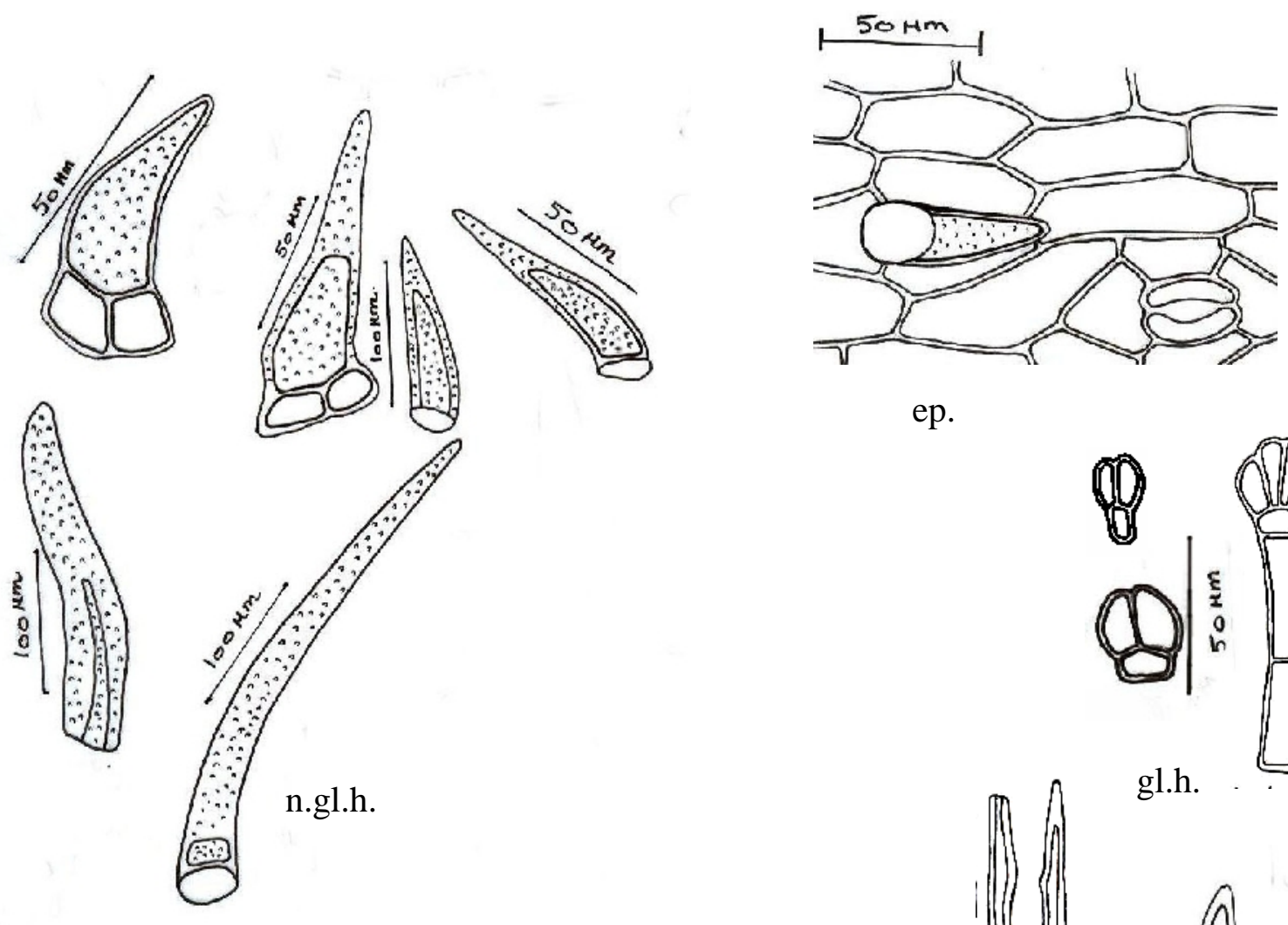

ep.

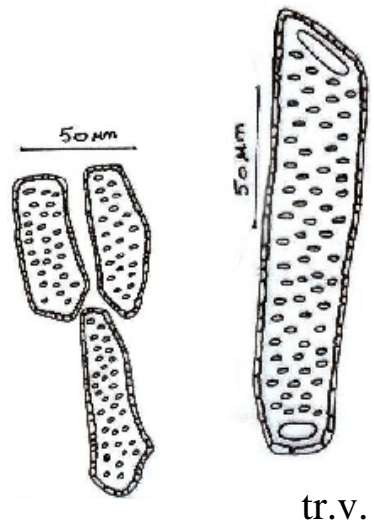

w.par.

tr.v.

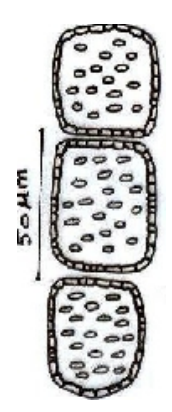

m.r.

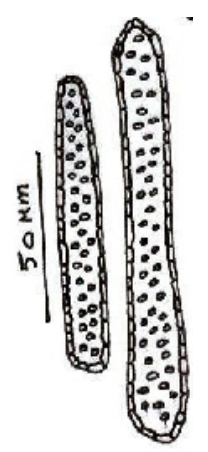

tr.
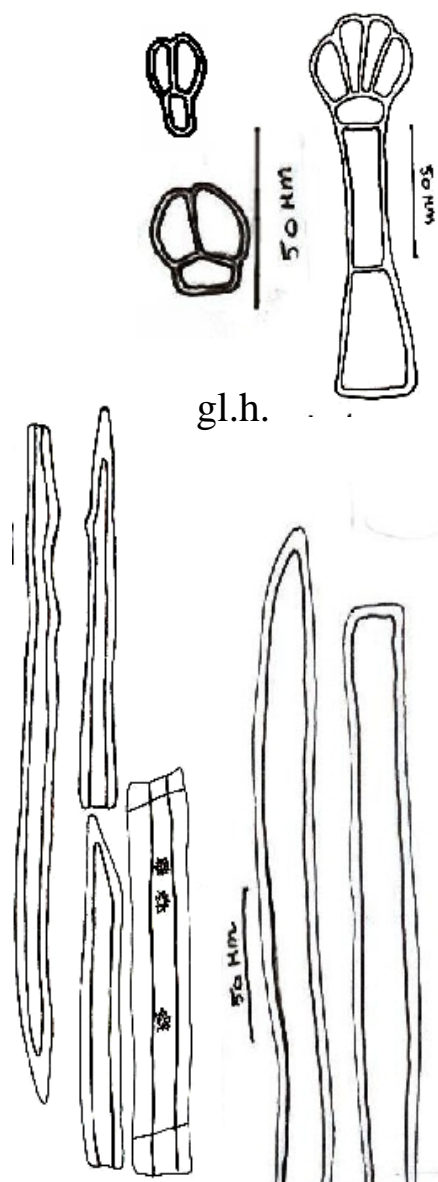

p.f.

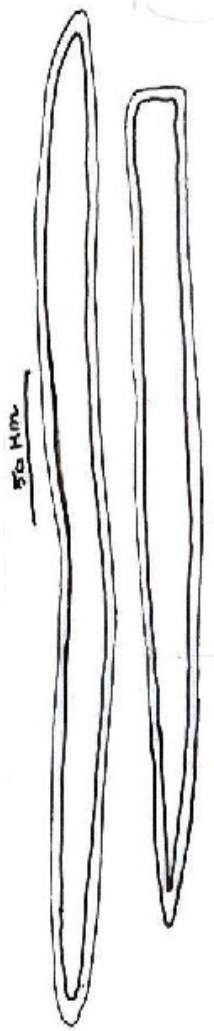

w.f.

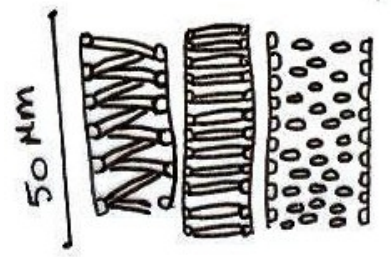

xy.v.

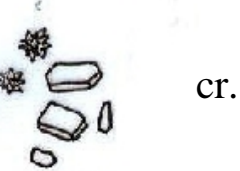

pi.

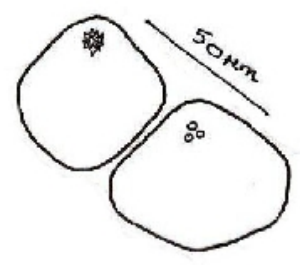

r.

Fig. 12: Powder of the young stem.

cr., crystal; ep., epidermis; gl.h., glandular hair; m.r., medullary ray; n.gl.h., non-glandular hair; p.f., pericyclic fiber; pi., pith; st.g., starch granules; tr., tracheids; tr.v., tracheidal vessels; w.f., wood fiber; w.par., wood parenchyma; xy.v., xylem vessels. 


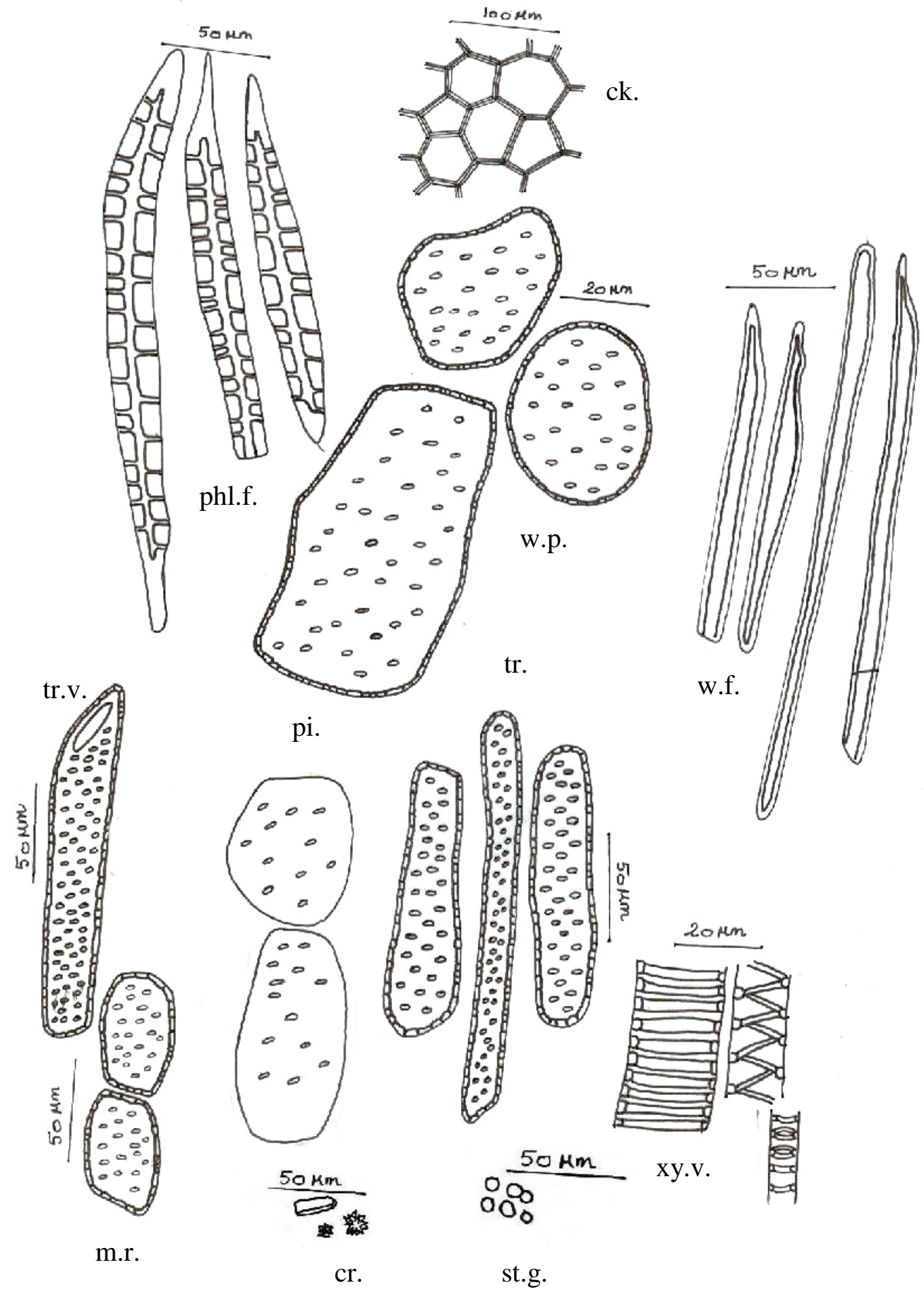

Fig. 13: The powder of the old stem.

ck., cork; cr., crystal; m.r., medullary ray; pi., pith; phl.f., phloem fiber; st.g., starch granules; tr., tracheids; tr.v., tracheidal vessels; w.f., wood fiber; w.p., wood parenchyma; xy.v., xylem vessels. 


\section{The powder}

The powder of young stem (Fig. 12) has green colour, slight aromatic odour and slight bitter astringent taste. It shows the following fragments:

1- Fragments of epidermal cells which are axially elongated subrectangular with more or less straight or slightly curved anticlinal walls. The cells are covered with thick smooth cuticle showing oval to rounded stomata of rananculaceous type. Hairs of both types, covering and glandular trichomes are present. The covering trichomes are unicellular, with broad bases, acute to acuminate apices and covered with warty cuticle. The glandular hairs are of two types, one has a unicellular stalk and a bicellular head (divided vertically as that of the digitalis) and the other has a bicellular stalk and multicellular head of 3 to 5 cells.

2- Scattered entire or fractions of glandular and non-glandular hairs.

3- Fragments of pericyclic fibers which have relatively thin refractive walls and comparatively wide lumens. Their ends are pointed and acuminate. Few of them are septated with one to two transverse septa dividing their lumens and containing cluster crystals of calcium oxalate in their lumens.

4- Fragments showing pitted, spiral, scalariform and annular xylem vessels.

5- Fragments showing lignified pitted wood parenchyma and medullary ray cells.

6- Fragments showing lignified pitted tracheids, tracheidal vessels and fibrous tracheids.

7- Occasional prismatic and cluster crystals of calcium oxalate either free or enclosed in parenchymatous cells.

8- Few small rounded or oval simple starch granules.

9- Fragments of wood fibers which have wide lumens, thick walls and blunt to rounded ends.

10- Fragments of parenchyma cells from the pith containing crystals of calcium oxalate and starch granules.

The powder of old stem (Fig. 13) has light brown colour, slight odour and a slight bitter astringent taste. It shows the following fragments:
1- Fragments of the cork cells which are polygonal and isodiametric cells.

2- Fragments of the phloem fibers which have relatively narrow lumens, thick shining walls, showing funnel shaped pits and acute tapering ends.

3- Fragments showing annular, scalariform, spiral and pitted xylem vessels.

4- Fragments showing lignified pitted wood parenchyma and medullary cells

5- Fragments showing lignified pitted tracheids and tracheidal vessels.

6- Fragments of prismatic and cluster crystals of calcium oxalate either free or enclosed in the parenchymatous cells.

7- Few small rounded or oval simple starch granules.

8- Fragments of wood fibers which have wide lumens, thick walls and blunt to rounded ends.

9- Fragments of pitted parenchyma cells from the pith containing crystals of calcium oxalate and starch.

\section{THE INFLORESCENCE}

\section{A- Macromorphology}

\section{The inflorescence (Fig. 2A)}

The flowers are yellow in colour, grouped in a terminal simple racemose inflorescence, which is a head like, compressed corymb, carrying the flowers in an acropital succession. The peduncle is conical and solid. The inflorescence is long pedicellate, having green, cylindrical, erect, and pubescent pedicle, measuring from 2 to $5 \mathrm{~cm}$ in length and from 2 to $3 \mathrm{~mm}$ in diameter. The whole inflorescence measures from 1 to $2 \mathrm{~cm}$ in length and from 2 to $4 \mathrm{~cm}$ in breadth at its middle portion. The odour is strongly aromatic while the taste is aromatic and slightly bitter.

The floret: (Fig. 14A)

It is sessile; each arises in the axil of the bract. The florets are beautifully yellow coloured. They are small in size from 0.5 to 1 $\mathrm{cm}$ in length and from 2 to $4 \mathrm{~mm}$ in diameter, having aromatic odour and slightly bitter astringent taste. The florets are hermaphrodite, zygomorphic, with the floral formula:

$$
\%, \sigma^{\prime \prime}, \mathrm{K}_{(4)}, \overparen{\mathrm{C}_{(4)}} \mathrm{A}_{4}, \mathrm{G}_{(\underline{(2)}}
$$




\section{The bract (Fig. 14B)}

It is concave ovate to lanceolate, sessile, with a wide base. It has a membranous texture, entire margin, acuminate apex and pale green colour. Three main veins cross the bract from base to apex and from which distinct lateral ones arise. The surface of the bract is hairy and the hairs are numerous at the apex. It measures from 2 to $5 \mathrm{~mm}$ in length and from 1 to $2 \mathrm{~mm}$ in width.

\section{The calyx (Fig. 14C)}

It is deciduous, gamosepalous, of four united sepals forming a tube, pale green in colour, reaching in size from 2 to $4 \mathrm{~mm}$ in length and $0.1 \mathrm{~mm}$ in thickness. There are 4 main veins traversing each sepal and give out lateral ones. The surface is hairy and membranous in texture.

\section{The corolla (Fig. 14D)}

It is gamopetalous formed of one whorl of 4 united pubscent, yellow petals. The corolla is funnel shaped and is contracted at its lower part into a comparatively long tubular claw, which reaches to about $3 / 4$ of the total length of the corolla. It shows 4 small lobes which are reniform-orbicular in outline, at its rim the lateral 2 lobes are smaller than the other two. Through the claw 4 main veins pass, that gave numerous branches traversing the upper lobes of the petals. The corolla ranges from 5 to 15 $\mathrm{mm}$ in length and from 3 to $5 \mathrm{~mm}$ in diameter.

\section{The androecium (Fig. 14D)}

The flower is tetrandrous, possessing four, free, epipetalous stamens, arranged in one whorl of 2 long and 2 short stamens, i.e didynamous. Filaments are filiform yellowishbrown in colour. Anther is small, green bilobed and attached at its base to the tip of the filament, i.e basifixed. The stamens reach up to $4 \mathrm{~mm}$ in length.

\section{The gynoecium (Fig. 14E)}

It is composed of 2 united carpels, forming one locule. The ovary is brown in colour, glabrous except for few hairs at the top at one side, sessile, superior and globular to ovoid in shape. It carries at the top an angular, cylindrical, pale brownish, glabrous and simple style, together with a small, oval, brown, papillosed stigma. The ovary measures $1 \mathrm{~mm}$ in diameter and from 1 to $1.5 \mathrm{~mm}$ in length while the style measures from 2 to $2.5 \mathrm{~mm}$ in length.

\section{B- Micromorphology}

\section{The Bract}

\section{The upper epidermis (Inner surface) (Fig. 15A, B\&C)}

The epidermal cells vary in size and shape according to their position. The cells of the apical region are polygonal in surface view, being more or less isodiametric with straight anticlinal walls. At the middle region the cells become longer, axially elongated, polygonal and possess straight somewhat curved anticlinal walls. The cells at the basal region are polygonal, mainly isodiametric, with straight anticlinal walls. The upper epidermis covered with smooth cuticle. Stomata of rananculaceous type are present but becoming rare at the basal region. They are rounded to oval in shape. Trichomes of both glandular and non-glandular types are present. They are more numerous at the apical region and becoming rare at the base. The non-glandular trichomes are unicellular, conical in shape with wide lumens and solid tapering tips and covered with warty cuticle. The glandular trichomes have unicellular stalks and globular or oval heads which may be unicellular, bicellular (the oval head is divided vertically into 2 cells as that of the digitalis $)^{12 \& 13}$ or tricellular. Abundant prismatic, rod like and cluster crystals of calcium oxalate are present.

\section{The lower epidermis (outer surface): (Fig. 15D, E\&F)}

It is more or less similar to the upper epidermis. The cells of the apical region are polygonal in surface view, more or less isodiametric with straight anticlinal walls. At the middle region the cells are longer, axially elongated, polygonal with straight anticlinal walls. The cells at the basal region are polygonal, isodiametric to axially elongated with straight anticlinal walls. The lower epidermal cells are covered with smooth cuticle. Trichomes of both types, stomata and crystals of calcium oxalate are present, being similar to those of the upper epidermis in all aspects. 


\section{The calyx}

\section{The upper epidermis (inner surface) (Fig. 16A, B\&C)}

The upper epidermal cells of the calyx have different sizes and shapes at different regions of the surface. The cells of the apical region are papillosed, polygonal in surface view, isodiametric, with curved aniclinal walls. At the middle region, the cells are papillosed, polygonal, isodiametric with straight slightly curved anticlinal walls. At the base, they are small isodiametric with straight anticlinal walls. The upper epidermal cells are covered with smooth cuticle. Few stomata of the rananculaceous type are present which are similar to those of the bract in all characters. Trichomes of both glandular and non-glandular types are common and becoming rare at the basal part. They are exactly identical to those of the bract in all characters.

\section{The lower epidermis (outer surface) (Fig. 16D, E\&F)}

The lower epidermal cells show distinct variation in size and shape according to their position on the surface. At the apical region, the cells are papillosed, polygonal in surface view, mainly elongated sometimes isodiametric with wavy anticlinal walls. At the middle region, the cells are papillosed, polygonal, axially elongated with wavy to sinuated anticlinal walls. The papillae are seen as small circles or triangles in the centre of the cells. At the basal part, the cells are polygonal, isodiametric with straight slightly curved anticlinal walls. The lower epidermal cells are covered with smooth cuticle. Stomata of rananculaceous type are present but less in number at the basal region. They are similar to those of the bract in all respects. Trichomes of both types are common becoming rare at the basal part. They are exactly identical to those of the upper epidermis in all characters.

\section{Corolla}

The upper epidermis (inner surface): (Fig. 17A, B\&C)

The epidermal cells are covered with smooth cuticle, vary in size and shape at different regions of the inner surface. In surface view, the cells of the apical region, are papillosed, more or less polygonal, usually isodiametric with straight anticlinal walls. Towards the middle region, the epidermal cells become gradually larger in size. Towards the basal region the cells become gradually smaller in size, polygonal, with distinctly beaded, straight or curved anticlinal walls. Stomata of the rananculaceous type may occur in small number and oval to circular in shape. Trichomes of both glandular and non-glandular types are present. The non-glandular trichomes are unicellular, conical in shape with wide lumens and solid tapering tips and covered with warty cuticle. The glandular trichome consists of a unicellular or bicellular stalk and a globular or oval head which may be unicellular, bicellular (the oval head is divided vertically into 2 cells as that of the digitalis) ${ }^{12 \& 13}$ or multicellular up to 6 cells.

\section{The lower epidermis (outer surface): (Fig.} 17D, E\&F)

These cells also show marked variation in size and shape at different parts of the epidermis. The cells of the apical region are usually papillosed, polygonal, isodiametric, with more or less straight anticlinal walls. In the middle region of the petals, the lower epidermal cell, gradually become larger, rectangular to subrectangular, sometimes, isodiametric more or less elongated and the anticlinal walls are more wavy and beaded while towards the basal region, the cells become gradually smaller in size, polygonal and axially elongated with nearly distinctly thick beaded anticlinal walls. The cells of the lower epidermis are covered with smooth cuticle. Stomata of the rananculaceous type are present in few number and they are oval to circular in shape. Abundant trichomes of both glandular and non-glandular types are present in the middle region and they decrease gradually toward the apical and basal regions. They are similar to those of the upper epidermis in all characters.

\section{Androecium}

\section{The filament}

The epidermal cells of the filament (Fig. 18A) in surface view, they appear polygonal axially elongated cells with nearly straight, thin anticlinal walls and covered with striated cuticle.Stomata are absent. Trichomes of both types, glandular and non-glandular are present. 
The non-glandular trichome is unicellular covered with warty cuticle. The glandular one has a bicellular stalk and unicellular rounded to oval head.

\section{The anther}

It is formed of 2, usually, equal and elongated anther lobes which are attached together by connective tissue through which passes a small vascular strand represents the vascular system of the anther. The connective tissue is formed of small colourless, thin walled parenchymatous cells. Each lobe contains usually 2 equal pollen sacs, filled with pollen grains.

\section{The epidermis of the anther (Fig. 18B)}

It is formed of papillosed cells, in the surface view, they appear polygonal, axially elongated with thin nearly straight or curved, anticlinal walls. The papillae are triangular in surface view.

\section{The fibrous layer (Fig. 18C)}

It is composed of a single layer of cells with lignified bar-like thickenings. This layer is continuous around the anther-lobe except where the two pollen sacs meet. In surface view, the fibrous cells are more of less polygonal, with distinctly beaded walls.

\section{The pollen grains (Fig. 18D)}

They are spherical or subspherical, with smooth, minutely pitted exine. The mature pollen grains are yellow in colour. Each grain possesses three germ pores.

\section{The gynoecium}

\section{The ovary (Fig. 19)}

\section{The outer epidermis (Fig. 19A)}

In surface view, the cells appear polygonal isodiametric, with thick straight, anticlinal walls. The cells are covered with thick smooth cuticle. Few stomata of rananculaceous type are present which are circular or sometimes oval in shape. Hairs are rare confined to one side at the top of the ovary, where they are nonglandular, uniserriate multicellular from 3 to 4 cells and covered with smooth cuticle.

\section{The style}

The epidermis of the style (Fig. 19B) is formed of polygonal axially elongated, subrectangular cells, with thin straight, anticlinal walls. The cuticle is moderately thin and usually showing faint longitudinal striations. Few stomata of rananculaceous type are present which are mainly circular or sometimes oval in shape.

\section{The stigma}

It is circular mainly oval in outline with distinctly papillosed epidermis (Fig. 19C).

\section{The peduncle}

A transverse section of the peduncle (Fig. 20A) appears rectangular in outline, showing a hairy epidermis, and a comparatively narrow parenchymatous cortex with collenchymatous masses in the angles and limited with starchy endodermis. The vascular bundle is surrounded by a band of pericyclic fibers which increases in thickness at the corners. The phloem forms a narrow zone around the radiating lignified xylem. The pith is fairly wide, parenchymatous, containing calcium oxalate crystals as well as minute starch granules are of common occurrence.

\section{The epidermis}

The epidermis (Fig. 21) consists of one row of square or subrectangular cells with thick smooth cuticle. In surface view (Fig. 20B\& B'), the cells are polygonal mainly axially elongated sometimes isodiametric, with thin straight anticlinal walls. Stomata of ranaculaceous type are present which are oval or rounded in shape. Hairs of both glandular and non-glandular types are present. The non-glandular trichomes are unicellular, conical in shape with wide lumens and solid tapering tips and covered with warty cuticle. The glandular trichomes consist of unicellular and globular or oval heads which may be unicellular or bicellular (the oval head is divided vertically into 2 cells as that of the digitalis $)^{12 \& 13}$. Abundant prismatic, rod like and cluster crystals of calcium oxalate are present.

\section{The cortex (Fig. 21)}

It is formed of 3-4 rows of parenchymatous cells which are rounded in shape and showing subepidermal masses of collenchyma at the ridges. The parenchyma cells contain prismatic and cluster crystals of calcium oxalate. Yellowish brown resinous content are present in the cells being similar to those in the 
leaf. The resinous content dissolves in $70 \%$ alcohol and reprecipitate in re-addition of water ${ }^{13}$. The endodermis is formed of one layer of tabular cells, which contains few spherical and simple starch granules.

\section{The pericycle (Fig. 21)}

It consists of more or less a complete ring of lignified fibers which are interrupted by parenchyma cells. The groups of fibers are well developed in the ridges. These fibers have relatively thin refractive walls and comparatively wide lumens. Their ends are pointed and acuminate.

\section{The vascular system (Fig. 21)}

It consists of a wide continuous ring traversed by narrow rays.

The phloem: It is formed of a narrow ring, consists of shining thin walled soft cellulosic elements of sieve tubes, companion cells and phloem parenchyma. The phloem parenchyma cells are thin walled oval and somewhat rounded and containing occasional prismatic and cluster crystals of calcium oxalate.

The xylem: It consists of lignified pitted thickwalled, radially arranged elements. The vessels are mainly pitted, spiral and reticulate. They are accompanied by numerous lignified tracheids bearing simple pits. The wood parenchyma cells are thick walled and lignified. The medullary rays are mainly uniserriate, sometimes biseriate and composed of lignified rectangular cells.

\section{The pith (Fig. 21)}

It is a wide zone, formed of more or less polygonal, isodiametric, pitted parencymatous cells. It contains small starch granules, prismatic and cluster crystals of calcium oxalate which are similar to those of the cortex.

\section{Powder of the inflorescence (Fig. 22)}

It is yellow in colour, with agreeable aromatic odour and slightly bitter astringent taste. It is characterized by the following:

1- Fragments of the pericyclic fibers from the peduncle with wide lumens and acuminate ends, together with fragments of pitted lignified pitted wood parenchyma and tracheids from the peduncle.
2- Fragments of spherical and subspherical pollen grains with minutely pitted exine and 3 germ pores.

3- Fragments of epidermal cells of stigma, which are distinctly papillosed showing very long papillae.

4- Fragments of the fibrous layer of the anther, with polygonal elongated cells and having bar like thickenings.

5- Fragments of prismatic and cluster crystals of calcium oxalate either free or enclosed in the cells.

6- Fragments showing pitted, spiral and scalariform lignified xylem vessels.

7- Entire or fractions of the glandular and non-glandular hairs, the non-glandular hairs may be unicellular, conical with tapering rounded ends and covered with warty cuticle, or multicellular uniserriate trichomes from 3 to 4 cells and covered with smooth cuticle while the glandular ones have unicellular or sometimes bicellular stalks and bicellular or multicellular heads from 3 to 6 cells and covered with smooth cuticle.

8- Fragments of epidermal cells of the bract showing polygonal cells with more or less isodiametric with straight anticlinal walls, covered with smooth cuticle.

9- Fragments of epidermal cells of the peduncle showing polygonal cells, with axially elongated sometimes isodiametric, with straight anticlinal walls.

10- Fragments of epidermal cells of the sepals showing papillosed cells, polygonal in surface view, isodiametric, with curved aniclinal walls.

11- Fragments of the epidermal cells of the petals showing polygonal, axially elongated, with nearly distinctly thick beaded anticlinal walls.

12- Fragments of the epidermal cells of the ovary showing polygonal cells, which is usually isodiametric, with thick straight anticlinal walls. The cells are covered with thick usually smooth cuticle.

13- Fragments of the epidermal cells of the style showing polygonal axially elongated, subrectangular cells, with straight, anticlinal walls. The cuticle is moderately thin and usually showing very faint longitudinal striations. 
14- Fragments showing papillosed epidermal cells of the stigma.

15- Fragments of the epidermal cells of the filament showing polygonal axially

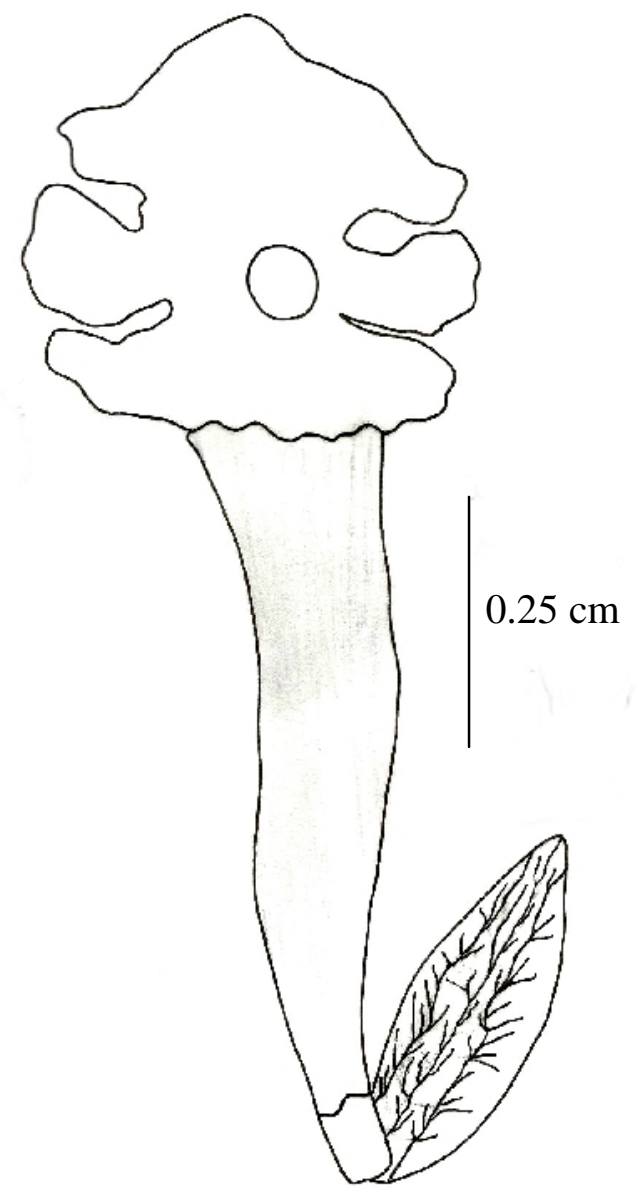

(A)

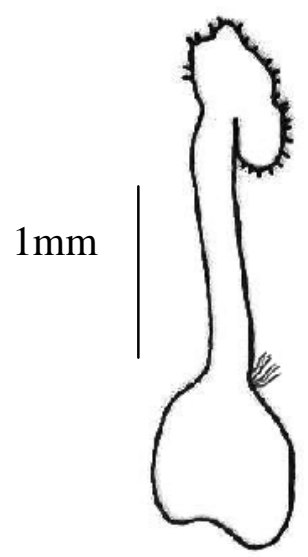

(E) elongated cells with thin, nearly straight or curved anticlinal walls and covered with striated cuticle.

(B)

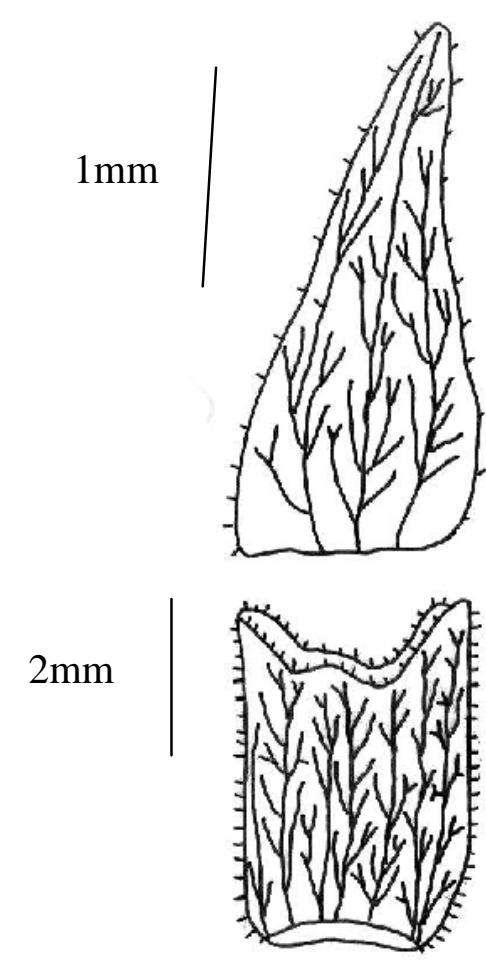

(C)

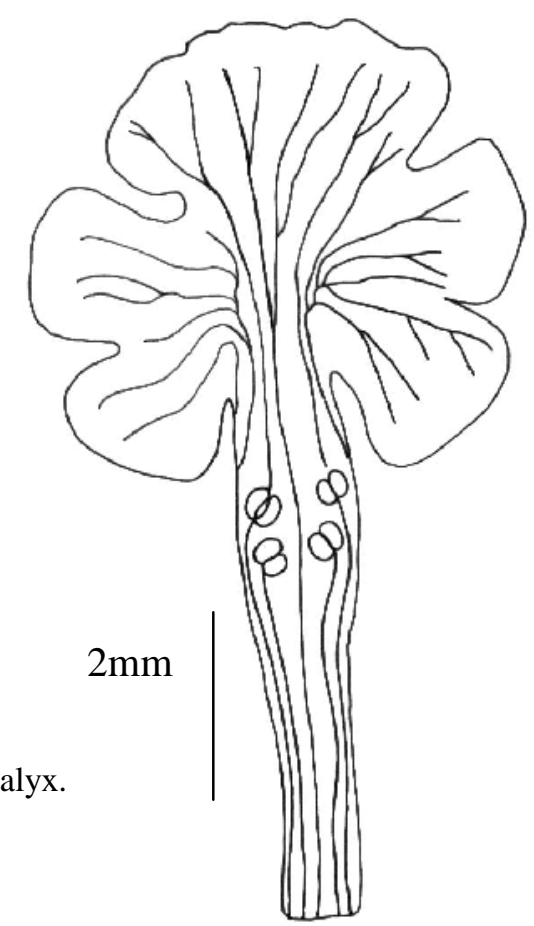

(D) 


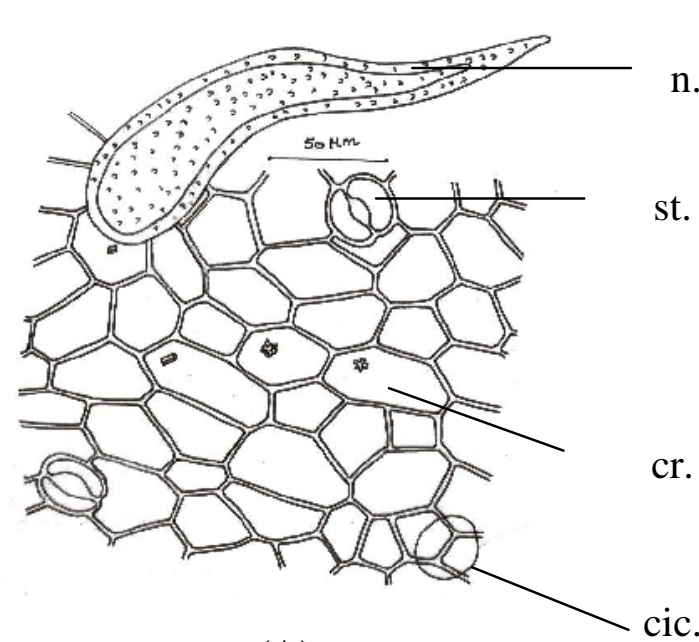

(A)
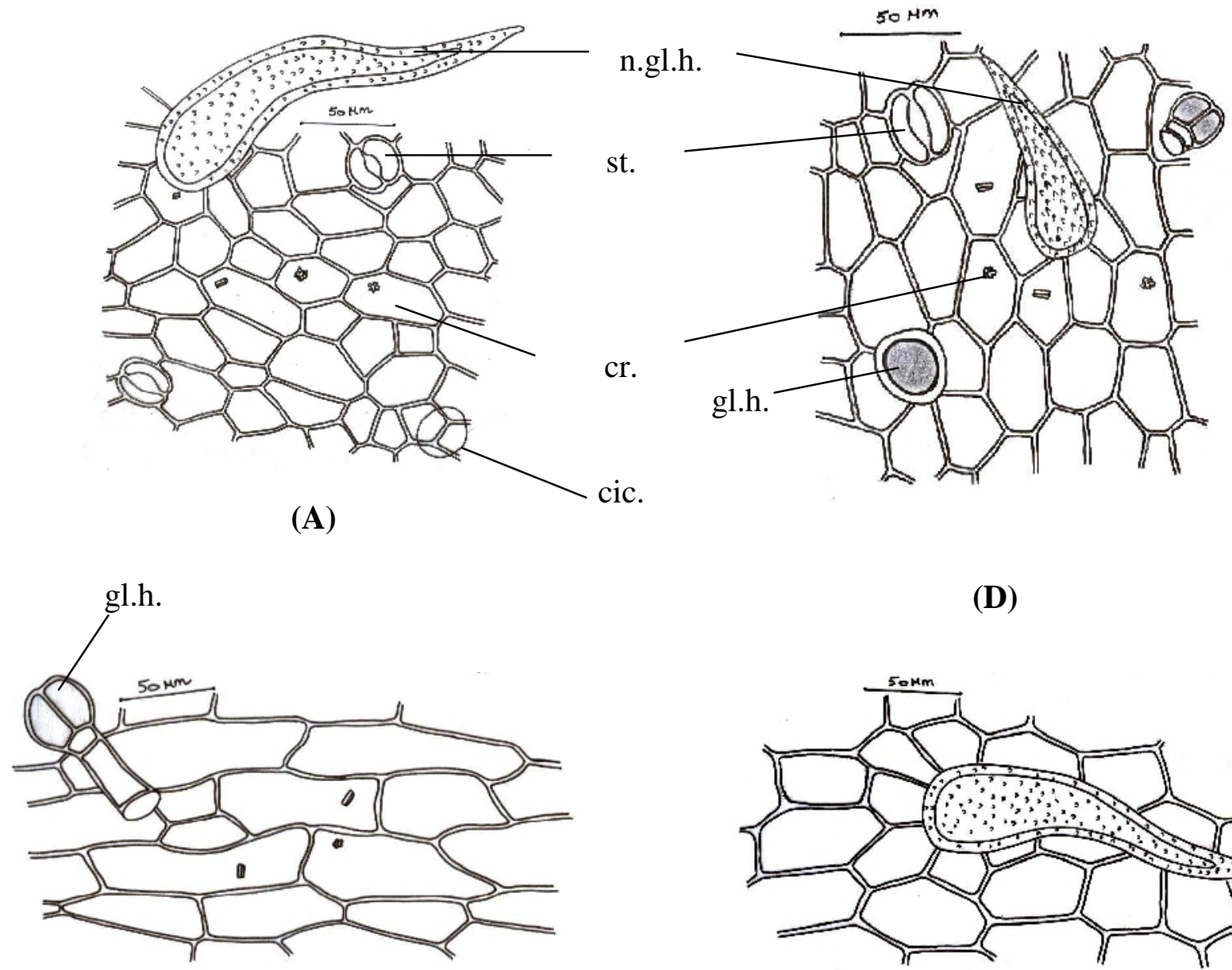

(D)

(B)

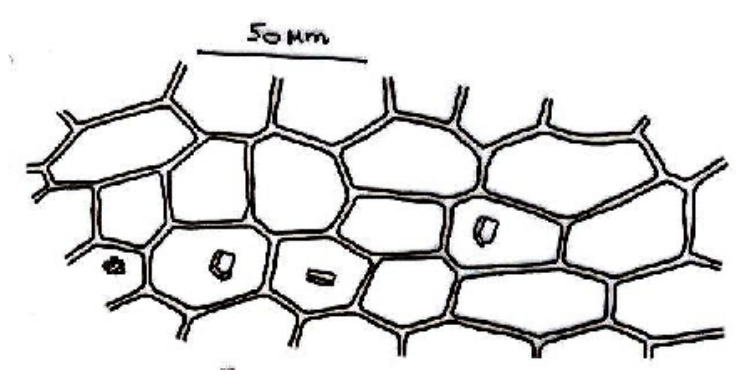

(C)

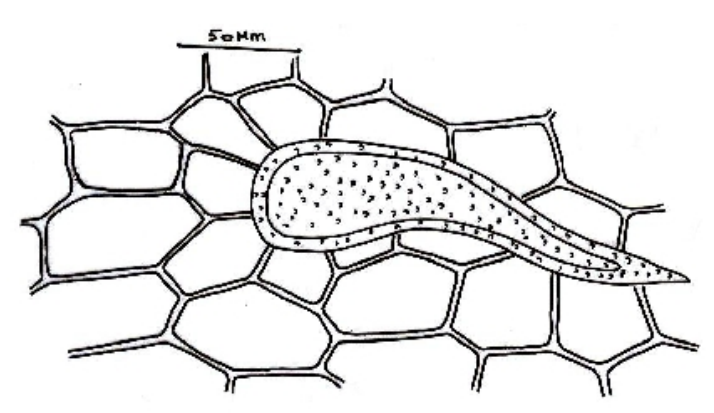

(E)

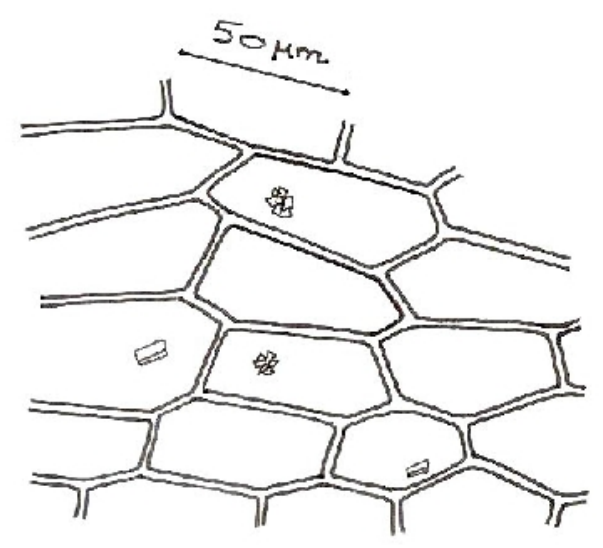

(F)

Fig. 15: (A) The apical upper epidermis of the bract.

(B) The middle upper epidermis of the bract.

(C) The basal upper epidermis of the bract.

(D) The apical lower epidermis of the bract.

(E) The middle lower epidermis of the bract.

(F) The basal lower epidermis of the bract.

cic., cicatrix; cr., crystal; gl.h., glandular hair; n.gl.h., non-glandular hair; st., stomata. 


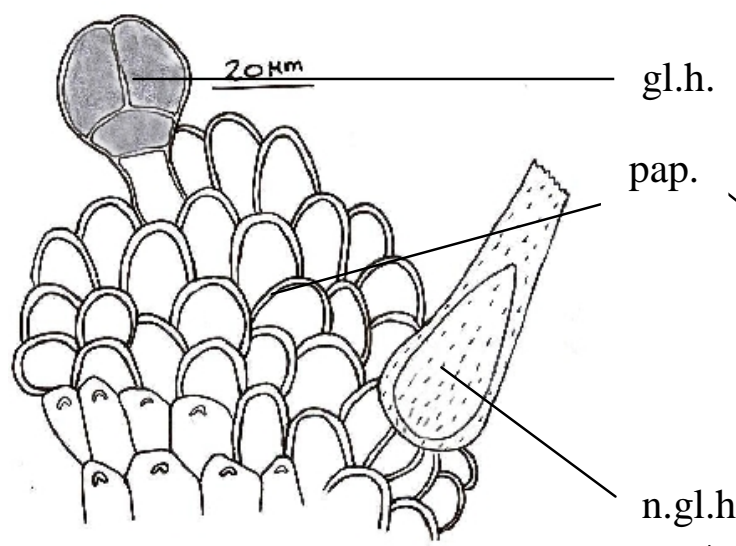

(A)

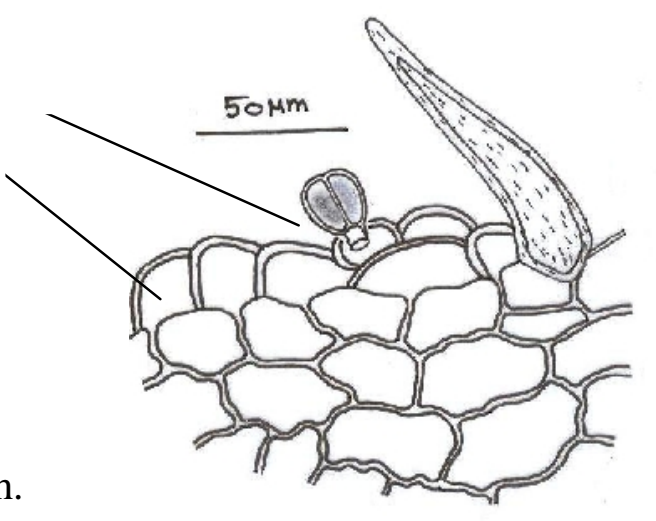

(D)

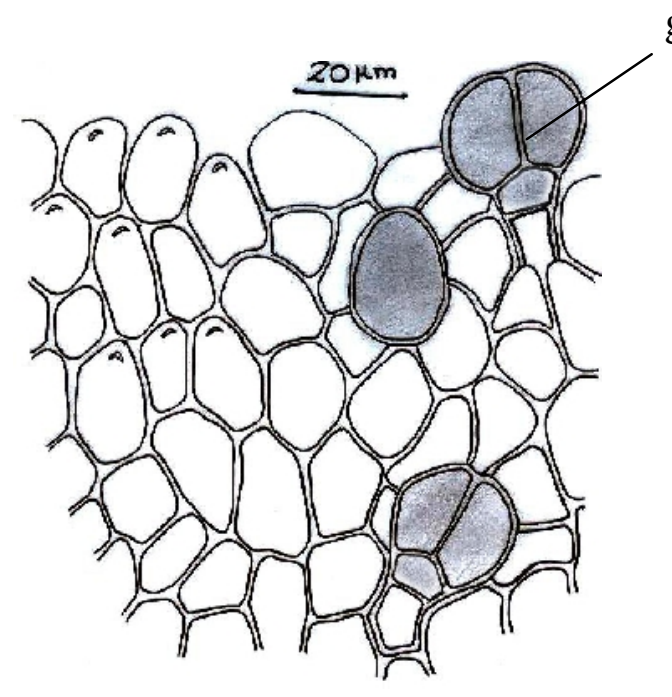

(B)

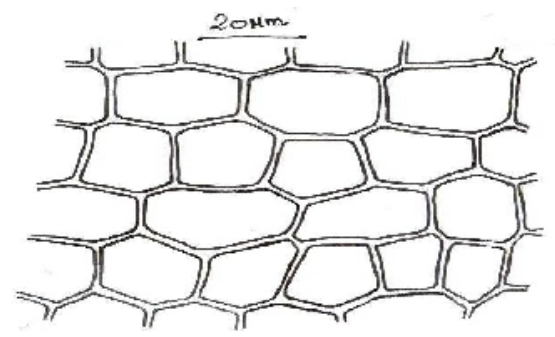

(C)

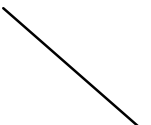

gl.h.

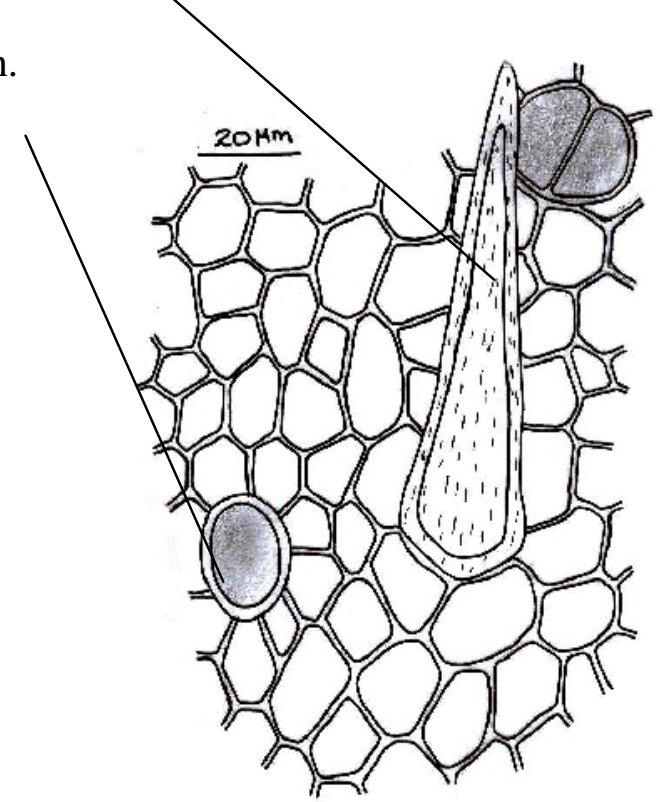

(E)

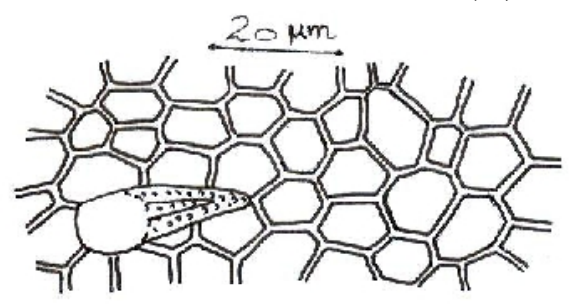

(F)

Fig. 16: (A) The apical upper epidermis of the sepals.

(B) The middle upper epidermis of the sepals.

(C) The basal upper epidermis of the sepals.

(D) The apical lower epidermis of the sepals.

(E) The middle lower epidermis of the sepals.

(F) The basal lower epidermis of the sepals.

gl.h., glandular hair; n.gl.h., non-glandular hair; pap., papillae. 


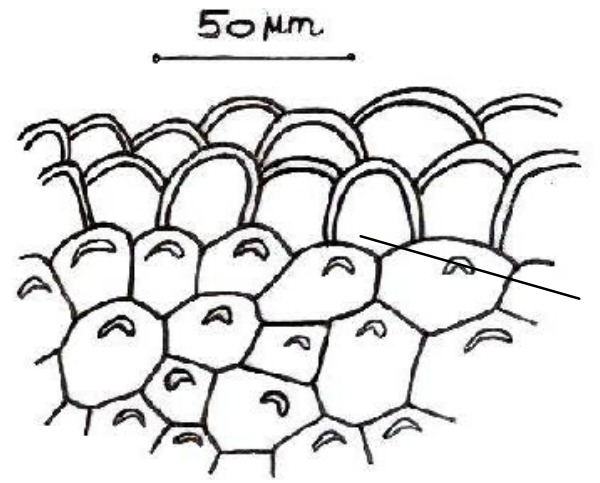

(A)

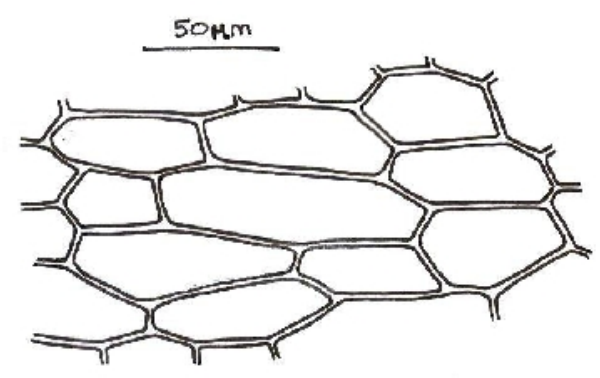

(B)

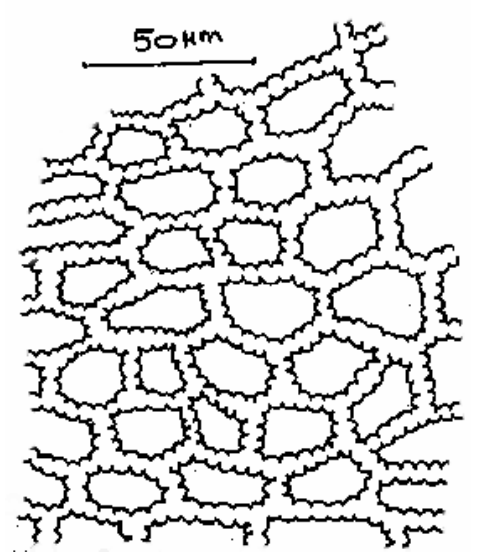

(C)

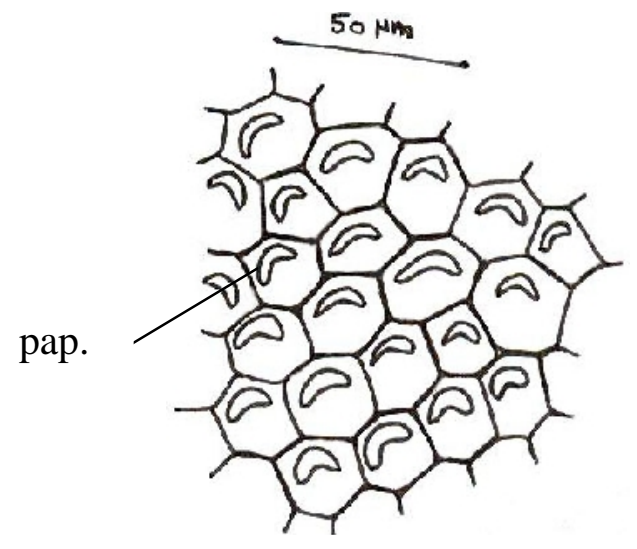

(D) n.gl.h.

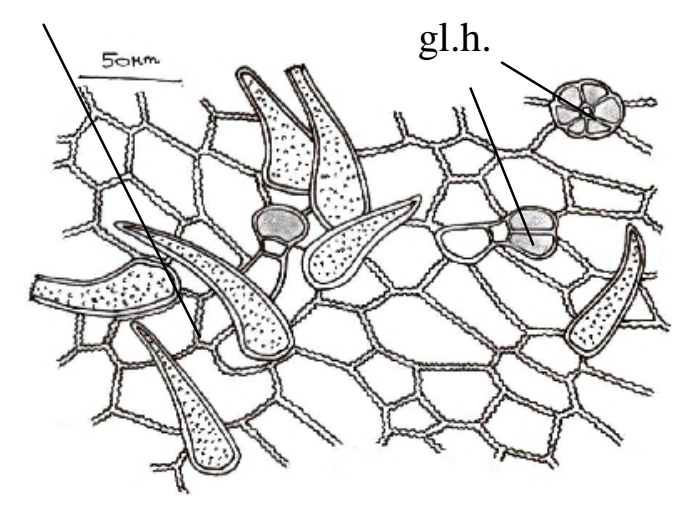

(E)

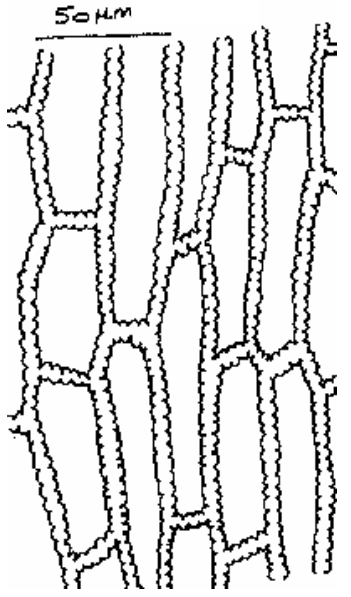

(F)

Fig. 17: (A) The apical upper epidermis of the petals.

(B) The middle upper epidermis of the petals.

(C) The basal upper epidermis of the petals.

(D) The apical lower epidermis of the petals.

(E) The middle lower epidermis of the petals.

(F) The basal lower epidermis of the petals.

gl.h., glandular hair; n.gl.h., non-glandular hair; pap., papillae. 


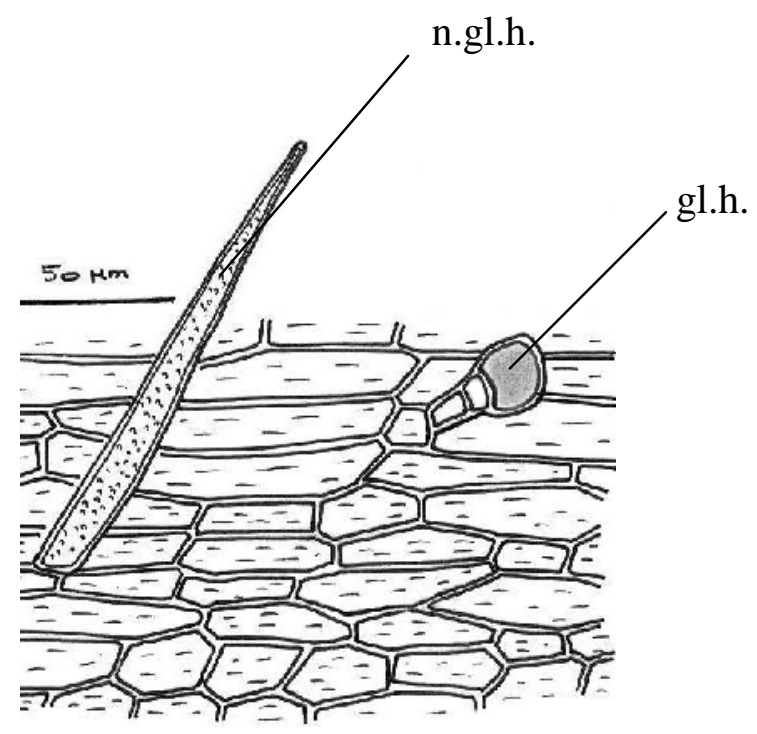

(A)

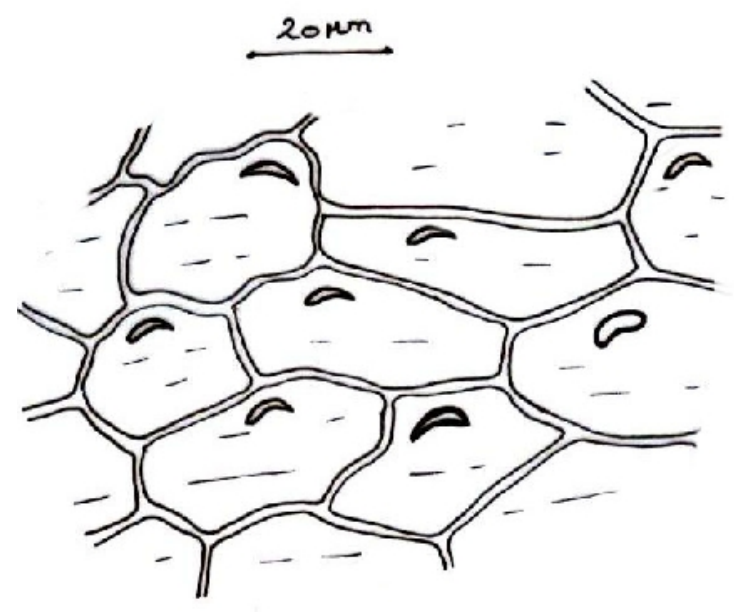

(B)

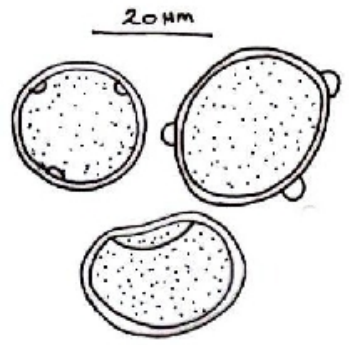

(D)

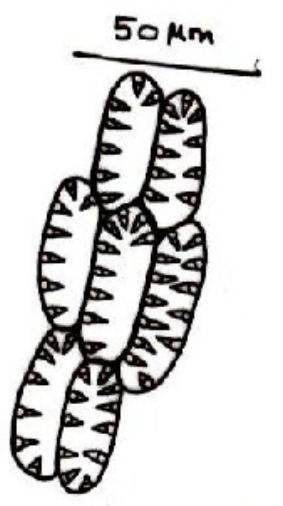

(C)

Fig. 18: (A) The epidermis of the filament.

(B) The epidermis of the anther.

(C) The fibrous layer of anther.

(D) The pollen grains.

gl.h., glandular hair; n.gl.h., non-glandular hair. 


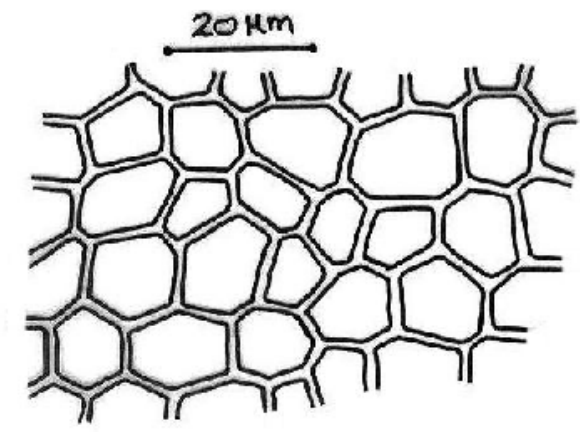

(A)

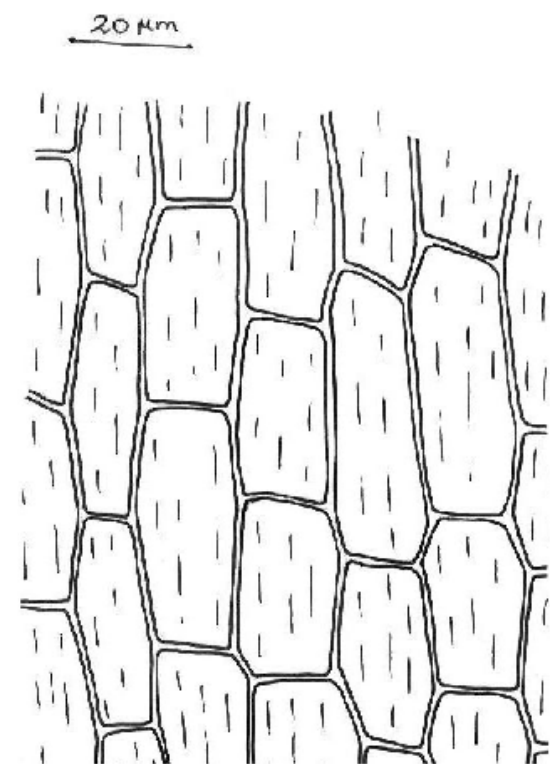

(B)

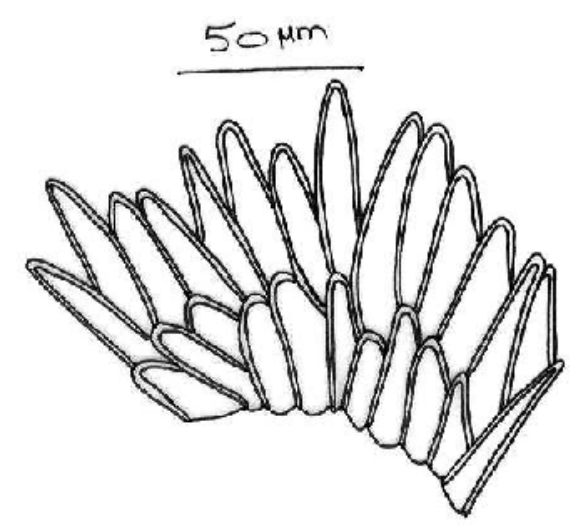

(C)

Fig. 19: (A) The epidermis of the ovary.

(B) The epidermis of the style.

(C) The papillosed stigma. 

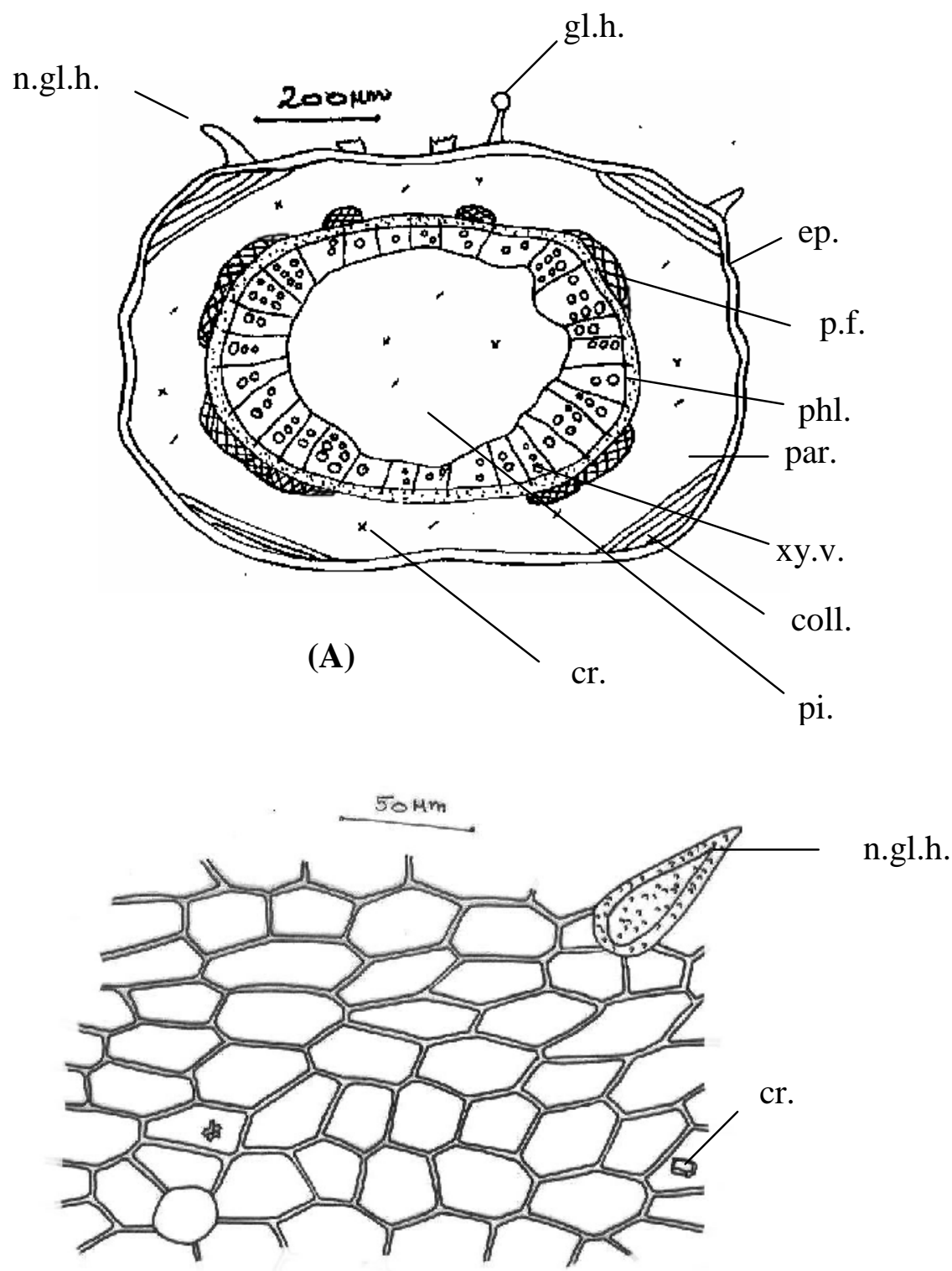

(B)

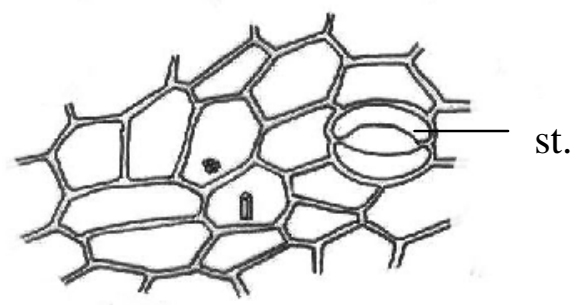

(B')

Fig. 20: (A) The diagrammatic T.S. of the peduncle.

(B) \& (B') The epidermis of the peduncle.

cic., cicatrix; cor., cortex; cr., crystal; ep., epidermis; gl.h., glandular hair; n.gl.h., non-glandular hair; p.f., pericyclic fibers; phl., phloem; pi., pith; st., stomata; xy.v., xylem vessel. 

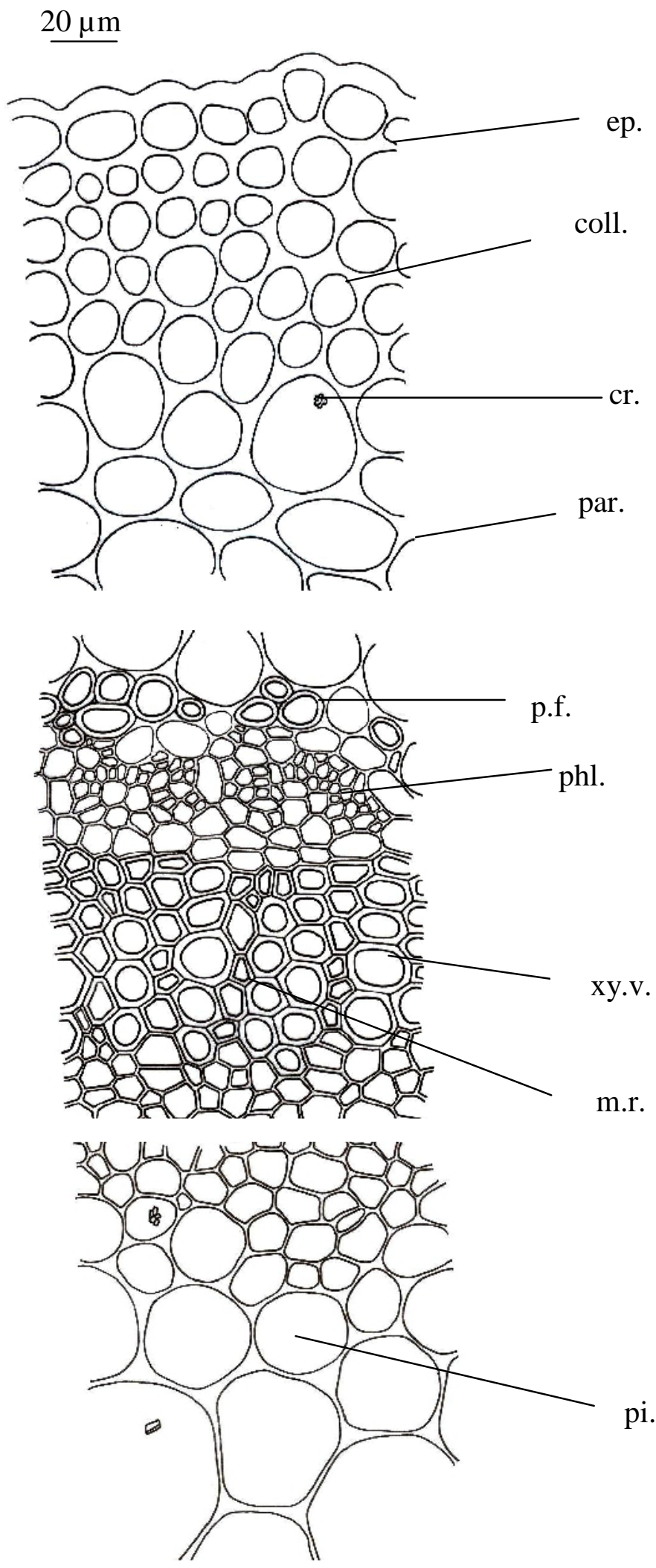

Fig. 21: The detailed T.S of the peduncle.

coll., collenchyma; cr., crystal; ep., epidermis; par., parenchyma; m.r., medullary ray; p.f., pericyclic fibers; phl., phloem; pi., pith; xy.v., xylem vessel. 


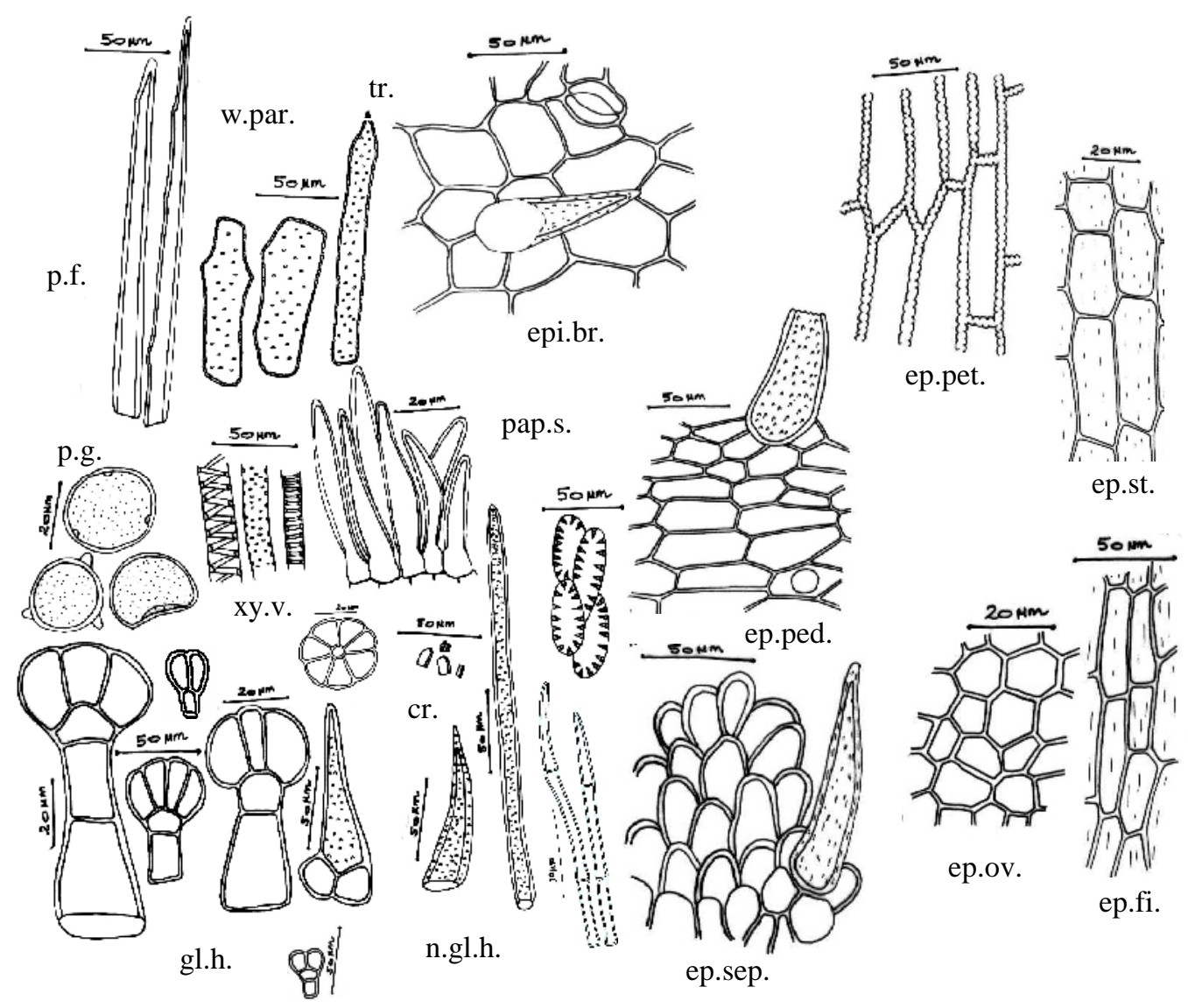

Fig. 22: Powder of the inflorescence.

cic., cicatrix, cr., crystal; ep.br., epidermis of the bract; ep.co., epidermis of the corolla; ep.fi., epidermis of the filament; ep.ov., epidermis of the ovary; ep.ped., epidermis of the peduncle; ep.pet., epidermis of the petals; ep.sep., epidermis of the sepals; ep.st., epidermis of the style; fib.l., fibrous layer of anther; gl.h., glandular hair; n.gl.h., non-glandular hair; pap.s, papillosed stigma; p.f., pericyclic fiber; p.g., pollen grains; tr., tracheids; w.par., wood parenchyma; xy.v., xylem vessels. 
Table 1: Microscopical measurements of the different organs of Lantana montevidensis (Spreng.) Briq.

\begin{tabular}{|c|c|c|c|c|}
\hline Item & Length & $\overline{\text { Width }}$ & Diameter & Height \\
\hline \multicolumn{5}{|l|}{ Leaf } \\
\hline Upper epidermis & $40-60-80$ & $25-40-55$ & & $14-26-37.5$ \\
\hline Lower epidermis & $27-46-65$ & $11.5-28.8-46$ & & $7-12.5-18$ \\
\hline Neural epidermis & $42-80.5-119$ & & & \\
\hline Stomata & $23-29-35$ & & $14-19-24$ & \\
\hline Palisade & $12-31-50$ & $6.2-10.8-15.5$ & & \\
\hline Parenchyma & & & $20-32.5-45$ & \\
\hline Collenchyma & & & $11.5-24.75-38$ & \\
\hline Chlorenchyma & & & $8-19-30$ & \\
\hline Xylem vessels & & & $5.5-12.25-19$ & \\
\hline Clusters & & & $5.7-\underline{8.5}-11.5$ & \\
\hline Prisms & $5.5-\underline{8.1}-10.7$ & $3.3-5.6-8.3$ & & \\
\hline Glandular hairs & $25-66.5-108$ & & $23.5-29.5-35.5$ & \\
\hline Non-glandular hair & $106-295.5-485$ & $13-31.5-50$ & & \\
\hline \multicolumn{5}{|l|}{ Petiole } \\
\hline Upper epidermis & $15.5-24.7-34$ & $12.5-\underline{23.25}-34$ & & $10-13.25-16.5$ \\
\hline Lower epidermis & $30.5-47-63.5$ & $11-18-25$ & & $10-\underline{15}-20$ \\
\hline Stomata & $23-29-35$ & & $14-19-24$ & \\
\hline Parenchyma & & & $16.5-31.75-34$ & \\
\hline Collenchyma & & & $12.5-28.2-44$ & \\
\hline Xylem vessels & & & $7-15.5-24$ & \\
\hline Clusters & & & $5.7-8.5-11.5$ & \\
\hline Prisms & $6.6-10.2-13.8$ & $3.3-5.6-8.3$ & & \\
\hline Glandular hairs & $25-66.5-108$ & & $23.5-29.5-35.5$ & \\
\hline Non-glandular hair & $106-295.5-485$ & $13-31.5-50$ & & \\
\hline Starch & & & $1.5-2.25-3$ & \\
\hline \multicolumn{5}{|l|}{ Young stem } \\
\hline Epidermal cells & $29.1-49.9-70.8$ & $10.4-17.7-25$ & & $6.6-9.9-13.3$ \\
\hline Stomata & $23-26.5-30$ & & $16.5-19.5-22.5$ & \\
\hline Collenchyma & & & $7.5-16.25-25$ & \\
\hline Parenchyma & & & $15-23.7-32.5$ & \\
\hline Pericyclic fibers & $350-\underline{639-928}$ & & $5-\underline{11.25}-17.5$ & \\
\hline Xylem vessels & & & $12-18.5-25$ & \\
\hline Wood parenchyma & $60-70-80$ & $12.5-18.75-25$ & & \\
\hline Wood fiber & - & & - & \\
\hline Medullary rays & $20-27.5-35$ & $12.5-22-31.5$ & & \\
\hline Tracheids & $86.8-106.3-126$ & $7.8-9.6-11.5$ & & \\
\hline Clusters & & & $5-\underline{6.5-8}$ & \\
\hline Prisms & $6.25-11-15.7$ & $2.5-\underline{4.5}-6.5$ & & \\
\hline Starch & & & $2-3.25-4.5$ & \\
\hline Glandular hairs & $30-137.5-245$ & & $25-31.25-37.5$ & \\
\hline Non.glandular hair & $117.5-245.1-375$ & $20-\underline{30-40}$ & & \\
\hline \multicolumn{5}{|l|}{ Old stem } \\
\hline Cork cells & $36.4-47.6-59$ & $40.9-50-59$ & & $8.75-13.7-18.75$ \\
\hline Parenchyma of the pith & & & $17-40-62.8$ & \\
\hline Phloem fibers & $268-214-260$ & & $16.6-21.4-23.8$ & \\
\hline Xylem vessels & & & $18-26.6-35.2$ & \\
\hline Wood parenchyma & $30.5-52.3-74.11$ & 7-23-39 & & \\
\hline Wood fiber & $-225-300$ & & $6-12-18$ & \\
\hline Medullary rays & $17.2-37.3-57.5$ & $11.4-23.2-35$ & & \\
\hline Tracheids. & $125.5-157.7-190$ & $13.9-20.3-26.7$ & & \\
\hline
\end{tabular}




\begin{tabular}{|c|c|c|c|c|}
\hline Item & Length & Width & Diameter & Height \\
\hline Clusters & & & $7.5-10-12.5$ & \\
\hline Prisms & $10-13.5-17$ & & & \\
\hline Starch & & & $4.8-5.5-6.25$ & \\
\hline \multicolumn{5}{|l|}{$\begin{array}{l}\text { Inflorescence: } \\
\text { Bract }\end{array}$} \\
\hline Upper epidermis (Apical) & $19.2-38.45-57.7$ & $11.5-21.2-30.7$ & & \\
\hline Upper epidermis(Middle) & $44.4-85.2-126$ & $16.07-25.8-35.7$ & & \\
\hline Upper epidermis(Basal) & $52.9-61.1-69.4$ & $15.2-24.3-33.3$ & & \\
\hline Lower epidermis(Apical) & $22.2-41.65-61.1$ & $11.11-20.8-30.5$ & & \\
\hline Lower epidermis(Middle) & $40-52.08-62.5$ & $22.7-30.6-38.6$ & & \\
\hline Lower epidermis(Basal) & 19.4-44.4-69.4 & $16.6-23.5-30.5$ & & \\
\hline \multicolumn{5}{|l|}{ Calyx } \\
\hline Upper epidermis (Apical) & $10.9-16.3-21.8$ & $7.2-11.13-15$ & & \\
\hline Upper epidermis(Middle) & $9-\underline{16.5-24}$ & $7-\underline{12-17}$ & & \\
\hline Upper epidermis(Basal) & $12-16-26$ & $12-14-16$ & & \\
\hline Lower epidermis(Apical) & $22.2-36.1-50$ & $8.3-16.6-25$ & & \\
\hline Lower epidermis(Middle) & $8.8-16.6-24.4$ & $6.6-11.08-15.5$ & & \\
\hline Lower epidermis(Basal) & $11.9-19.05-26.2$ & $8.3-15.4-22.6$ & & \\
\hline \multicolumn{5}{|l|}{ Corolla } \\
\hline Upper epidermis (Apical) & $16.6-23-29.5$ & $15.9-23.8-31.8$ & & \\
\hline Upper epidermis(Middle) & $33.8-\overline{66.9}-100$ & $20.5-24.9-29.4$ & & \\
\hline Upper epidermis(Basal) & $13.6-23.8-34$ & $9-11.3-13.6$ & & \\
\hline Lower epidermis(Apical) & $18.1-21.5-25$ & $19.3-23.2-27.2$ & & \\
\hline Lower epidermis(Middle) & $28.5-51.7-75$ & $14.2-26.7-39.2$ & & \\
\hline Lower epidermis(Basal) & $75-100-125$ & $14.3-22.7-31.2$ & & \\
\hline \multicolumn{5}{|l|}{ Androecium } \\
\hline Pollen grains & & & & $25-28-31$ \\
\hline Fibrous layer of anther & $40-50-60$ & $8-12.03-16.07$ & & \\
\hline Epidermis of anther & $23.3-36.6-50$ & $13.3-19.1-25$ & & \\
\hline Epidermis of filament & $18.75-40.6-62.5$ & $6.25-11.6-17.1$ & & \\
\hline \multicolumn{5}{|l|}{ Gynoecium } \\
\hline Epidemis of stigma & $31.25-\underline{48.75-66.25}$ & & & \\
\hline Epidermis of style & $18.1-\overline{33.6}-49.1$ & $10.9-13.6-16.3$ & & \\
\hline Epidermis of ovary & & & $8.2-11.35-15.3$ & \\
\hline \multicolumn{5}{|l|}{ Peduncle: } \\
\hline Epidermial cells & $23.5-\underline{39.6}-55.8$ & $11.7-\underline{19}-26.4$ & $8.75-\underline{11.8-15}$ & \\
\hline Collenchyma & & & & $7.5-\underline{12.5-17.5}$ \\
\hline Parenchyma of cortex & & & & $20-28.5-37.1$ \\
\hline Pericyclic fibers & $150-200-270$ & $5.7-12.8-20$ & & \\
\hline Xylem vessels & & & & $10-\underline{15-20}$ \\
\hline Tracheids & $55-105-155$ & $13.5-15.5-17.5$ & & \\
\hline Wood parenchyma & $70-\underline{86.25}-102.5$ & $10-22.5-35$ & & \\
\hline Parenchyma of pith & & & & $17.1-41-65$ \\
\hline \multicolumn{5}{|l|}{ General flower } \\
\hline Stomata & $23-25.3-27.7$ & & & $19-22.9-26.9$ \\
\hline Non-glandular hair & $59.5-152.2-245$ & $12.5-28.5-44.5$ & & \\
\hline Glandular hair & $27.7-5 \overline{58.85-90}$ & & & $19.4-\underline{33.45-47.5}$ \\
\hline Cluster & & & & $3.2-\underline{5.1-7}$ \\
\hline Prism & $5.5-7.1-8.8$ & & & \\
\hline Starch granules & & & & $2-2.5-3$ \\
\hline
\end{tabular}




\section{REFERENCES}

1- G. H. M. Lawrence, "Taxonomy of Vascular Plants", The Macmillan Co., New York, 1951, pp. 686-688.

2- S. C. Datta, "A Hand Book of Systematic Botany", $2^{\text {nd }}$ Ed, Asia Publishing House, Bombay, 1970, pp. 310-312.

3- L. E. Core, "Plant Taxonomy", PrenticeHall, Englewood Cliffs, New Jersey, 1955, p. 402.

4- M. Hickey and C. King, "100 Families of Flowering Plants", $2^{\text {nd }}$ Ed, Cambridge University Press, Great Britain, 1988, pp. 385-386.

5- A. A. Munir, "A Taxonomic review of Lantana camara L. and Lantana montevidensis (Spreng.) Briq. (Verbenaceae) in Australia", J. Adelaide Botanic Gardens, 17 (1), 1-27 (1996).

6- E. L. Ghisalberti, "Lantana camara L. (Verbenaceae)/Review", Fitoterapia, 71 (5), 467-486 (2000).

7- H. Hussain, J. Hussain, A. Al-Harrasi and Z. K. Shinwari, "Chemistry of some species genus Lantana", Pakistan J. of Botany, 43 (SI), 51-62 (2011).

8- O. P. Sharma and S. Sharma. "A review of the hepatotoxic plant Lantana camara", Critical Reviews in Toxicology, 37 (4), 313-352 (2007).
9- T. Nagao, F. Abe, J. Kinjo and H. Okabe, "Antiproliferative consitiuents in plants 10. Flavones from the leaves of Lantana montevidensis Briq. and consideration of structure-activity relationship", Biological \& Pharmaceutical Bulletin, 25 (7), 875879 (2002).

10- R. M. Montanari, L. C. A. Barbosa, A. J. Demuner and C. J. Silva, "Chemical composition and antibacterial activity of essential oils from Verbenaceae species: Alternative sources of $(E)$-caryophyllene and germacrene- D", Quimica Nova, 34 (9), 1550-1555 (2011).

11- E. O. Sousa, F. F. G. Rodrigues, H. D. M. Coutinho, A. R. Campos, S. G. Lima and J. G. M. Costa, "Chemical composition and aminoglycosides synergetic effect of Lantana montevidensis Briq. (Verbenaceae) essential oil", Records of Natural Products, 5 (1), 60-64 (2011).

12- C. R. Metcalfe and L. Chalk, "Anatomy of Dicotyledons", The Clarendon Press, Oxford, Vol , 1950, pp. 1030-1041.

13- S. M. El-Sayyad, "Pharmacognostical Study of Lantana camara L. Grown in Egypt", M. Sc. Thesis, Faculty of Pharmacy, Pharmacognosy Dept., Assuit University, Egypt (1970). 


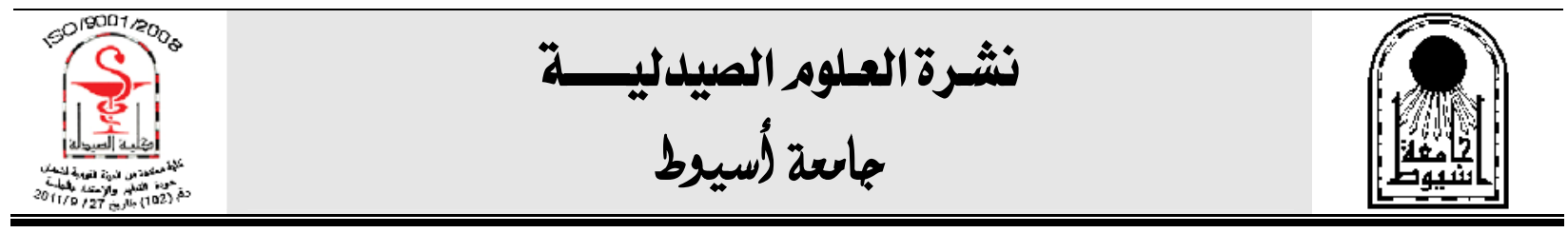

دراسة عيانية ومجهرية للأجزاء الهوائية لنبات اللانتانا مونتفدنسيز

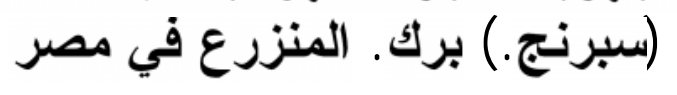

مقبول احمد مقبول - احمد عابدين عطيه - سلوى فاروق فرج - نسمه مصطفى كمال

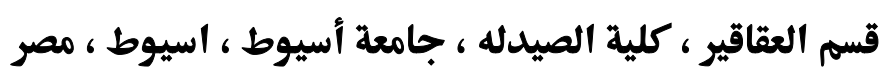

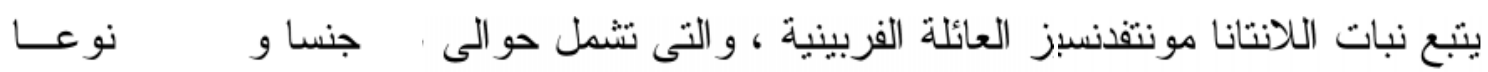

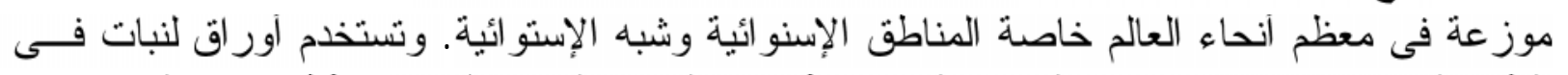

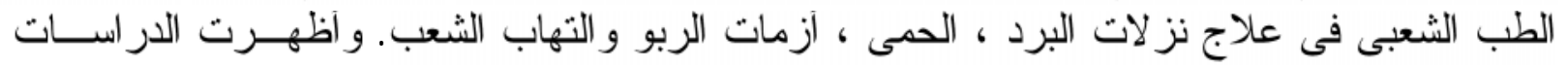

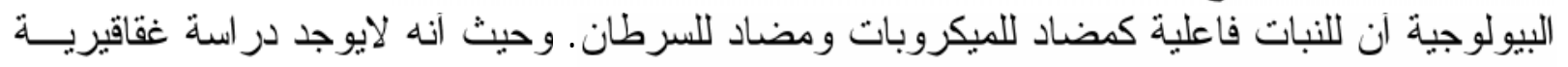

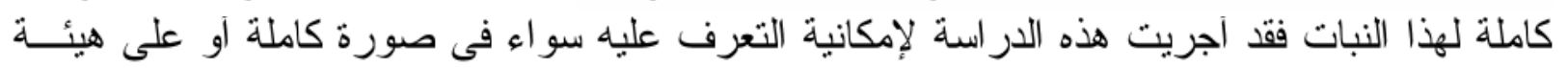
مسحوق. كامل لنا 